University of South Florida

DIGITAL COMMONS

@ UNIVERSITY OF SOUTH FLORIDA
Digital Commons @ University of

South Florida

8-1-2008

\title{
Performance Measures and Best Practices for Incorporating Transit into the FDOT DRI Review Process
}

CUTR

Follow this and additional works at: https://digitalcommons.usf.edu/cutr_nctr

\section{Recommended Citation}

"Performance Measures and Best Practices for Incorporating Transit into the FDOT DRI Review Process," National Center for Transit Research (NCTR) Report No. CUTR-NCTR-RR-2006-09, Center for Urban Transportation Research, University of South Florida, 2008.

DOI: https://doi.org/10.5038/CUTR-NCTR-RR-2006-09

Available at: https://scholarcommons.usf.edu/cutr_nctr/25

This Technical Report is brought to you for free and open access by the National Center for Transit Research (NCTR) Archive (2000-2020) at Digital Commons @ University of South Florida. It has been accepted for inclusion in Research Reports by an authorized administrator of Digital Commons @ University of South Florida. For more information, please contact digitalcommons@usf.edu. 


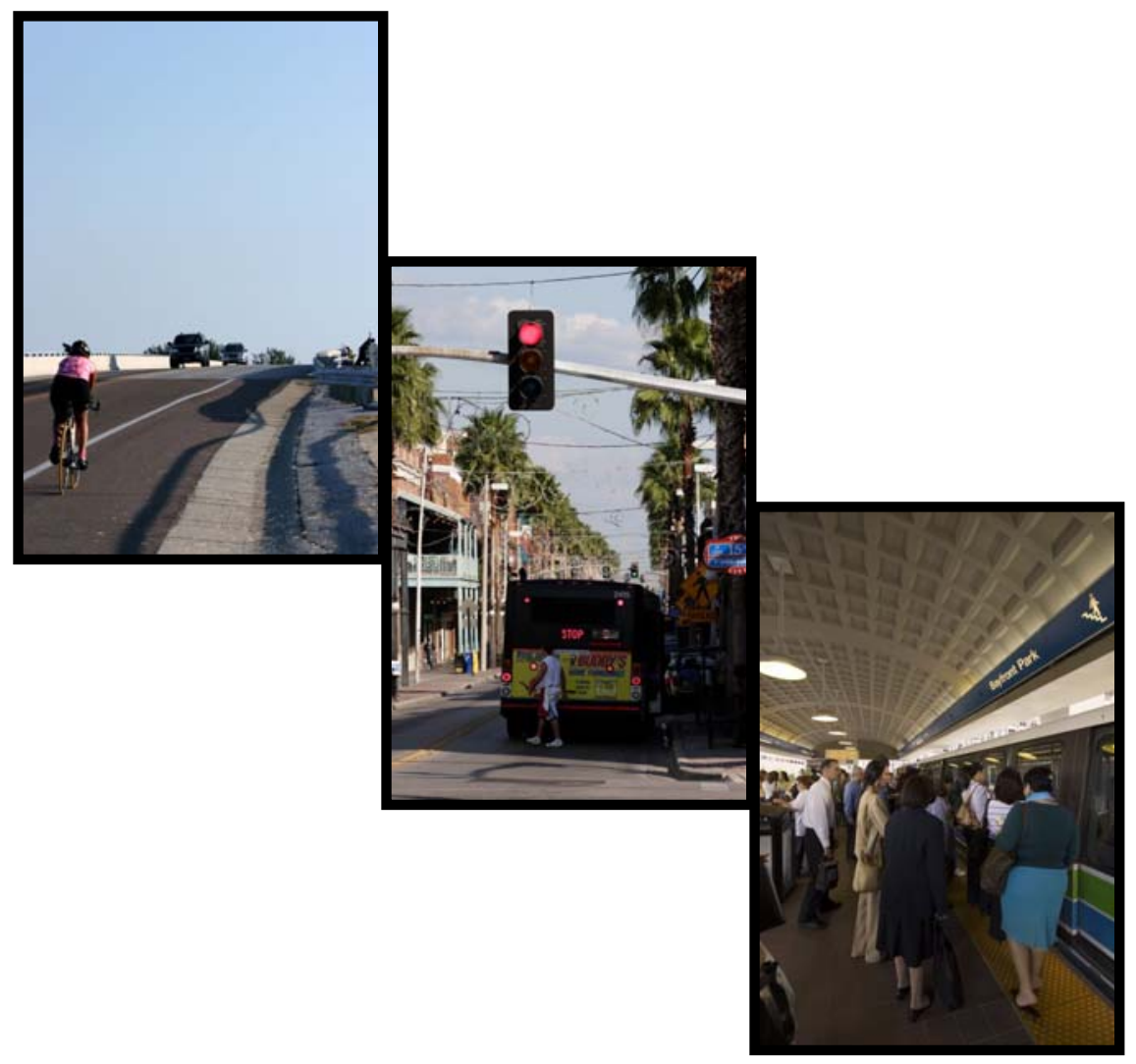

\section{Guidelines and Performance Measures to Incorporate Transit and Other Multimodal Considerations} into the FDOT DRI Review Process

FDOT Contract Number: BD549, RPWO \#31 August 2008

National Center for Transit Research Center for Urban Transportation Research University of South Florida 
This research was conducted under a grant from the Florida Department of Transportation. The opinions, findings, and conclusions expressed in this publication are those of the authors and not necessarily those of the Florida Department of Transportation. 


\begin{tabular}{|c|c|c|}
\hline $\begin{array}{l}\text { 1. Report No. } \\
\text { BD549, RPWO \#31 }\end{array}$ & 2. Government Accession No. & 3. Recipient's Catalog No. \\
\hline \multirow{2}{*}{\multicolumn{2}{|c|}{$\begin{array}{l}\text { 4. Title and Subtitle } \\
\text { Guidelines and Performance Measures to Incorporate Transit and Other } \\
\text { Multimodal Considerations into the FDOT DRI Review } \\
\text { Process }\end{array}$}} & $\begin{array}{l}\text { 5. Report Date } \\
\text { August } 2008\end{array}$ \\
\hline & & 6. Performing Organization Code \\
\hline \multicolumn{2}{|c|}{$\begin{array}{l}\text { 7. Author(s) } \\
\text { Karen E. Seggerman, AICP, Sara J. Hendricks, AICP, and } \\
\text { Ann C. Joslin }\end{array}$} & $\begin{array}{l}\text { 8. Performing Organization Report No. } \\
2117-7703-00\end{array}$ \\
\hline \multirow{2}{*}{\multicolumn{2}{|c|}{$\begin{array}{l}\text { 9. Performing Organization Name and Address } \\
\text { National Center for Transit Research } \\
\text { Center for Urban Transportation Research } \\
\text { University of South Florida } \\
\text { 4202 E. Fowler Ave., CUT 100, Tampa, FL } 33620\end{array}$}} & 10. Work Unit No. (TRAIS) \\
\hline & & 11. Contract or Grant No. \\
\hline \multirow{2}{*}{\multicolumn{2}{|c|}{$\begin{array}{l}\text { 12. Sponsoring Agency Name and Address } \\
\text { Florida Department of Transportation Research Center } \\
605 \text { Suwannee Street, Tallahassee, FL } 32399\end{array}$}} & 13. Type of Report and Period Covered \\
\hline & & 14. Sponsoring Agency Code \\
\hline
\end{tabular}

15. Supplementary Notes

16. Abstract

FDOT staff participates in the review of developments of regional impact (DRIs) to evaluate impacts on the state transportation system using guidance in the FDOT "Site Impact Handbook” (Handbook). This review, via DRI Question 21, allows for the consideration of transit and other alternative modes of transportation; however, because few applicants include a detailed multimodal analysis as part of their application, there is little information available for FDOT review and comment. Further, there are no specific guidelines for FDOT staff regarding how to incorporate transit and other multimodal strategies into DRI reviews.

This report supplements the instructions for performing DRI reviews in the "Site Impact Handbook" with specific guidance on incorporating transit and other multimodal strategies in the DRI review process directed to FDOT staff and consultants. In some cases, this guidance may be applicable to other types of development review. Other transportation planning partners such as regional planning councils, metropolitan planning organizations, local governments, transit authorities and agencies, transportation management associations, and the development community may find these guidelines useful in the development review process.

17. Key Word

Multimodal, transit, bicycle, pedestrian, development of regional impact, review process, multimodal policy, transportation impact

18. Distribution Statement

\begin{tabular}{|l|l|l|l|}
\hline $\begin{array}{c}\text { 19. Security Classif. (of this report) } \\
\text { N/A }\end{array}$ & 20. Security Classif. (of this page) & 21. No. of Pages \\
75 & 22. Price &
\end{tabular}


FDOT Project Staff Tara Bartee, Public Transit Office Amy Datz, Public Transit Office Martin Guttenplan, Systems Planning Office Susan Sadighi, District 5 Planning

CUTR Project Staff

Karen E. Seggerman, AICP, Co-Principal Investigator Sara J. Hendricks, AICP, Co-Principal Investigator

Ann C. J oslin, Co-Principal Investigator Stephanie Bromfield, Graduate Research Assistant Monique Ellis, Graduate Research Assistant Rebecca Bosco, Program Assistant 


\section{Executive Summary}

FDOT staff participates in the review of developments of regional impact (DRIs) to evaluate impacts on the state transportation system using guidance in the FDOT "Site Impact Handbook" (Handbook). This review, via DRI Question 21, allows for the consideration of transit and other alternative modes of transportation; however, because few applicants include a detailed multimodal analysis as part of their application, there is little information available for FDOT review and comment. Further, there are no specific guidelines for FDOT staff regarding how to incorporate transit and other multimodal strategies into DRI reviews.

This document contains recommended guidelines for enhancing DRI review to address alternative modes. It includes proposed policy language, information for applicants, an approach for considering alternative modes of transportation, mitigation strategies, and sample comment language. Adoption of a clearly articulated policy will convey the State's intent to FDOT District staff and consultants involved in DRI reviews. Such a policy along with these guidelines will result in consistent consideration of transit and other multimodal strategies. These guidelines also include recommended performance measures. These indicators specifically gauge the degree and quality of FDOT staff review of DRIs toward the desired outcome of incorporating transit and other multimodal strategies into developments of regional impact.

Building on the "Site Impact Handbook" criteria, this document suggests requesting additional information from the applicant to address all transportation modes including documenting existing conditions within the DRI study area, addressing land use and site design, and detailing access between the DRI and the surrounding community. Supplemental checklists serve to augment those in the Handbook. This document also provides example comments taken verbatim from sufficiency review letters, development order recommendations, notice of proposed change comments, and substantial deviation comments to serve as guidance for FDOT staff.

Finally, the document contains guidelines that focus on providing education and training, building relationships with local governments and other agencies, and conducting a peer exchange meeting to share information. Each FDOT district can influence mitigation strategies recommended by other reviewers by developing new or improving existing relationships with its transportation partners. By taking a lead role in advocating multimodal strategies to serve the DRI while maintaining adopted levels of service on regional transportation facilities, FDOT can be a leader regarding how transportation facilities are planned and coordinated with land development. 
[This page left blank intentionally.] 


\section{TABLE OF CONTENTS}

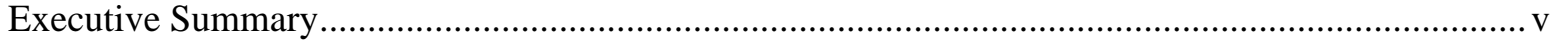

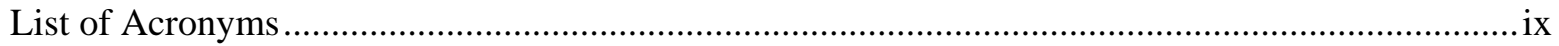

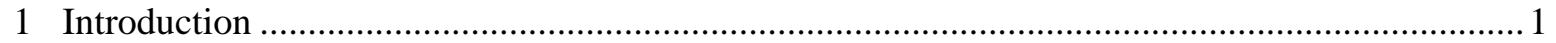

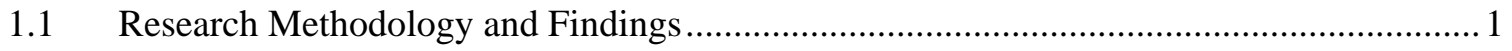

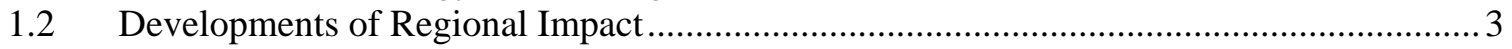

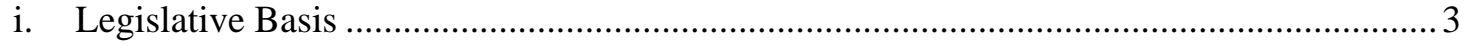

ii. Impacts to the State Highway System........................................................................ 4

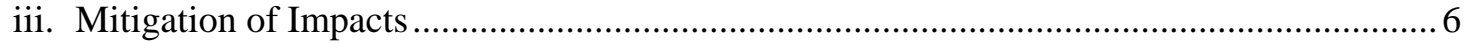

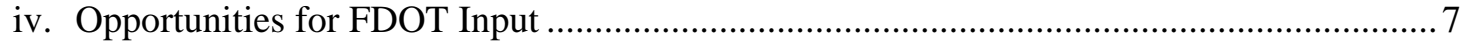

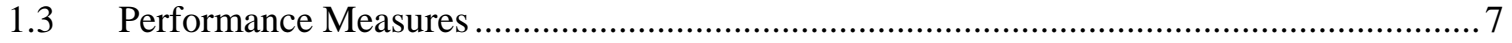

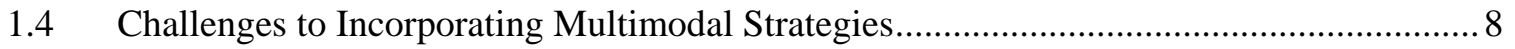

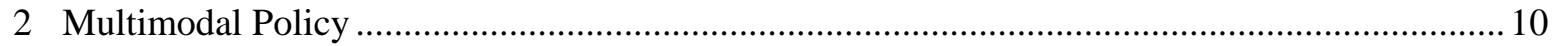

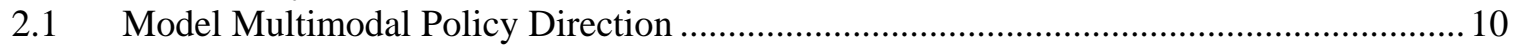

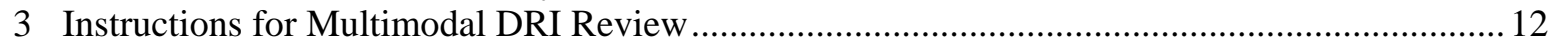

3.1 Preapplication Conference Format Meeting and Information for Applicant ..................... 13

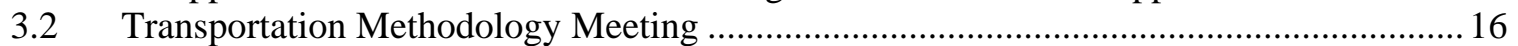

3.3 RPC Regional Issues List and Agency Comments ......................................................... 18

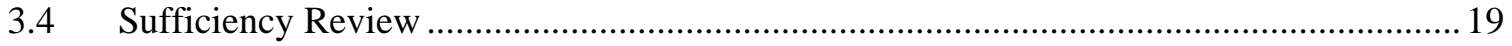

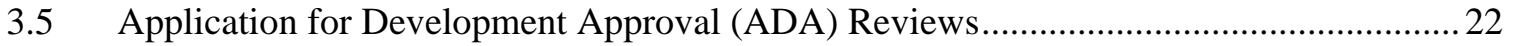

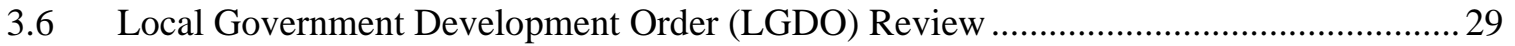

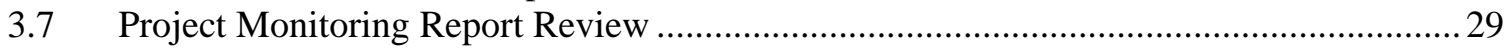

3.8 Notice of Proposed Change (NOPC) and Substantial Deviation Determination ............... 31

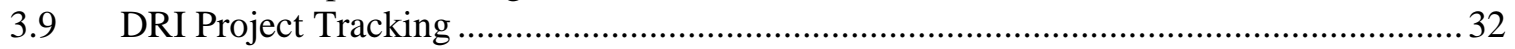

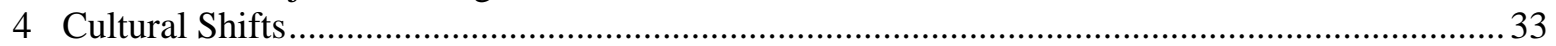

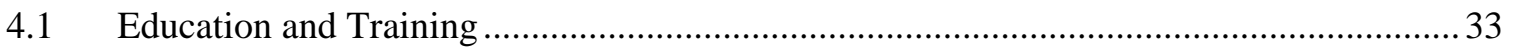

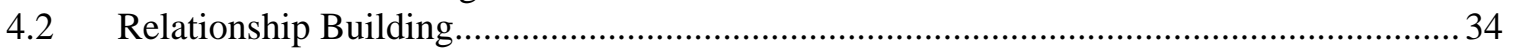

4.3 Multimodal Transportation Peer Exchange..................................................................... 35

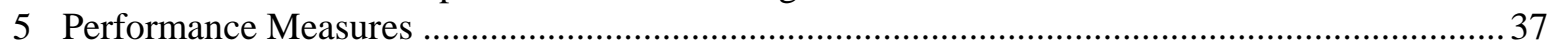

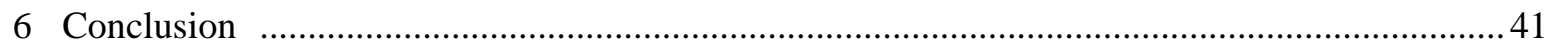

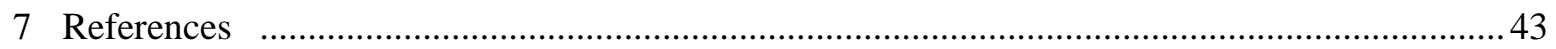

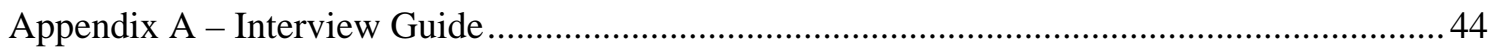

Appendix B - DRI Application for Development Approval Question 21 ................................ 46

Appendix C - Multimodal Information to be Provided or Made Available to DRI Applicant ... 48

Appendix D - Multimodal Connectivity Analysis............................................................... 55

Appendix E - Proposed Transportation Methodology Comments ............................................ 56

Appendix F - FDOT District 4 Example Office of Modal Development (OMD) Multimodal

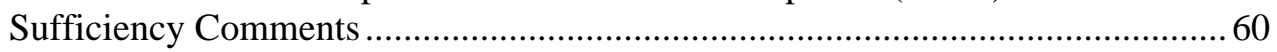

Appendix G - Hosting a Multimodal Solutions Peer Exchange Meeting.................................. 62 


\section{LIST OF TABLES}

TABLE 1 Information Provided/Available to Applicant Checklist - Multimodal Supplement............ 15

TABLE 2 Multimodal Information to be Included in the ADA .......................................................... 16

TABLE 3 DRI Checklist 1. Transportation Methodology Meeting Information Submittal Checklist -

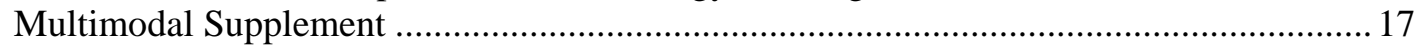

TABLE 4 DRI Checklist 2. DRI-ADA Sufficiency Checklist - Multimodal Supplement .................. 19

TABLE 5 DRI Checklist 3. DRI-ADA Review Checklist - Multimodal Supplement......................... 22

TABLE 6 DRI Checklist 4. Local Government Development Order Review Checklist - Multimodal Supplement

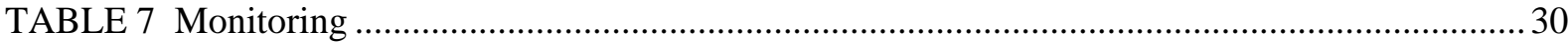

TABLE 8 Performance Measures for the DRI Review Process ......................................................... 38 


\section{LIST OF ACRONYMS}

ADA (DRI) application for development approval

ADA Americans with Disabilities Act

CMS concurrency management system

CUTR Center for Urban Transportation Research

DCA Department of Community Affairs

DO development order

DRI development of regional impact

F.A.C. Florida Administrative Code

FDOT Florida Department of Transportation

FIHS Florida Intrastate Highway System

FLUM future land use map

FPTA Florida Public Transportation Association

FTPN Florida Transit Planning Network

F.S. Florida Statute

GIS geographic information system

HOV high-occupancy vehicles

ISTEA Intermodal Surface Transportation Efficiency Act

LEED Leadership in Energy and Environmental Design

LGCP local government comprehensive plan

LOS level of service
LRTP long range transportation plan MMTD multimodal transportation district MPO metropolitan planning organization NEFRPC Northeast Florida Regional Planning Council

NOPC (DRI) notice of proposed changes

OMD (FDOT) Office of Modal Development

RPC regional planning council

SHS State Highway System

SIS Strategic Intermodal System

SOV single occupant vehicle

TBEST Transit Boardings Estimation and Simulation Tool

TCEA transportation concurrency exception area

TCMA transportation concurrency management area

TDM transportation demand management

TDP transit development plan

TEA-21 Transportation Equity Act for the $21^{\text {st }}$ Century

TMA transportation management association

TND traditional neighborhood development

VMT vehicle miles traveled 
[This page left blank intentionally.] 


\section{INTRODUCTION}

A development of regional impact (DRI) is a large-scale development expected to impact more than one county as defined in Florida Statutes (§380.06(1), F.S.). Each DRI is subject to a review process in which the regional planning council, the state, and affected jurisdictions and agencies have an opportunity to provide recommendations to a local government for assuring that regional impacts of the proposed DRI have been properly addressed. The primary purpose of the DRI review process is to provide the opportunity for multiple agencies to communicate and cooperate in identifying and addressing DRI impacts that cross jurisdictional boundaries. The Florida Department of Transportation's (FDOT) role in the DRI review process is specified in state law and is limited to assessing the impact of a proposed DRI on the State Highway System and recommending appropriate mitigation. In addition, the 2005 growth management legislation charged the Department to work with local governments and developers to ensure proposed mitigation measures would maintain mobility on the Strategic Intermodal System (SIS) and the Florida Intrastate Highway System (FIHS).

FDOT staff participates in DRI reviews throughout the state using the instructions and techniques in the FDOT "Site Impact Handbook" to evaluate development impacts to the State Transportation System. In addition, FDOT staff is tasked with reviewing the impacts of sub-DRI developments (large-scale development that falls below DRI thresholds), comprehensive plan amendments, and other development. Such reviews sometimes include the consideration of transit and other alternative modes of transportation; historically, however, they focus on motor vehicle impacts. As traffic congestion increases in urban areas and continually adding roadway capacity is neither feasible nor desirable, transit and other multimodal strategies are increasingly considered as means to maximize the capacity of the transportation system. These modes of transportation should be addressed as an integral part of the DRI review process as well as other development review processes to ensure a well-rounded transportation system.

This report supplements the instructions for performing DRI reviews in the "Site Impact Handbook" with specific guidance on incorporating transit and other multimodal strategies in the DRI review process directed to FDOT staff and consultants. In some cases, this guidance may be applicable to other types of development review. Other transportation planning partners such as regional planning councils, metropolitan planning organizations, local governments, transit authorities and agencies, transportation management associations, and the development community may find these guidelines useful in the development review process.

\subsection{Research Methodology and Findings}

The University of South Florida's Center for Urban Transportation Research (CUTR) researched and evaluated current FDOT processes and procedures for incorporating transit and other multimodal strategies into the DRI review process. The methodology for this research included interviews and a review of the laws and regulations pertaining to the review process, as well as the review of sufficiency comments and development orders to gain an understanding of the extent to which transit and other multimodal strategies are recommended and used as mitigation of DRI impacts. Over 45 interviews with individual stakeholders were conducted. Interviewees included public transit agency staff, regional planning council representatives and FDOT staff and its consultants representing all seven FDOT districts. An interview guide containing 33 questions covering the areas of DRI review processes, transit considerations in the process, development 
orders and monitoring, and staff resources, expertise and training provided a consistent framework for each interview for comparison purposes. The interview guide is included in Appendix A.

Through this effort, CUTR was able to gain the perspective of a broad base of practitioners on how the process currently works, what its limitations are, what challenges it poses, and what improvements can be made. The following is a summary of the research findings.

- Many proposed DRIs are located on the suburban fringe where large tracts of land are still available for development. These areas are often not served by transit, or if they are, the transit service may consist of only one route offering limited service. It has been difficult to project transit ridership that would lower the estimated trip generation of a proposed development thus mitigating anticipated traffic impacts on the adjacent road network. A recently developed tool, Transit Boardings Estimation and Simulation Tool ${ }^{1}$ (TBEST), will allow users to forecast ridership using demographic data and service characteristics.

- FDOT review of DRIs is focused primarily on motor vehicle impacts to the State Highway System, historically with little attention given to transit or other multimodal strategies. No explicit or implicit guidelines, policies, or procedures for reviewing the incorporation of transit and other multimodal strategies within DRIs were identified during the research. In addition, data regarding the analysis and application of transit in DRIs are not readily available.

- Each FDOT District conducts DRI reviews in its own way according to a protocol established by key personnel, many of whom have worked in the area of DRI review for years. While site impact training is available for all FDOT staff and consultants, there is not specific training for reviewing DRIs. With neither a formal procedure nor training for such reviews, FDOT DRI reviewers often learn by doing. In many cases, the same staff member has reviewed DRIs for as many as 20 years and has made few changes in his/her approach. FDOT District DRI coordinators rely heavily on consultants to review the traffic impact analyses submitted by DRI applicants. Consultants ensure that the traffic impact analysis adheres to FDOT's site impact analysis requirements and recommend mitigation of significant and adverse impacts of the proposed development on the State Highway System. Although FDOT Districts typically include a Public Transit Division that administers transit grants and oversees commuter assistance programs, these staff rarely play a role in DRI reviews.

- Development order conditions for mitigating DRI impacts focus on roadway improvements; transit-related conditions are rare. Both applicants and FDOT consultants focus on conventional solutions to maintaining level of service (LOS) on state roads. Such solutions include securing developers' contributions to widen existing trouble spots and to construct new highway facilities reflected in adopted work programs. While it is not a standard practice to consider transit in DRI mitigation solutions, Alachua, Broward, Hillsborough, Leon, Martin, Miami-Dade, Orange, and St. Johns are among jurisdictions that have recommended such conditions. It is anticipated that many more development orders will require multimodal conditions of approval.

\footnotetext{
${ }^{1}$ TBEST is a comprehensive transit analysis and ridership forecasting model that is capable of simulating travel demand at the individual stop-level while accounting for network connectivity, spatial and temporal accessibility, time-of-day variations, and route competition and complementarity. More information is available at http://www.tbest.org
} 
- FDOT's ability to advocate alternative modes in the DRI process is limited due to its advisory role. There is minimal interface between FDOT, local governments, and transit agencies with respect to multimodal considerations. When transit conditions are suggested, it is usually the regional planning council or the local government that requires the inclusion of transit or other modes. Because the Department does not own or maintain transit systems, staff is often reluctant to make transit-related recommendations.

- The use of transit or other multimodal strategies is rarely advocated for mitigation of DRI impacts due to the lack of a direct correlation between the provision of modal alternatives and the reduction of vehicle trips. As a result, it is very difficult for such transportation system improvements to meet statutory tests including:

- $\quad$ The transportation need that must be mitigated must be attributable to the proposed development paying for the mitigation.

- The amount of the contribution must correspond to the amount needed to mitigate the impacts from the development.

- $\quad$ The funds must go toward improvements to serve that development.

- $\quad$ Developers of DRIs cannot be required to contribute funds for mitigation unless the host local government has an ordinance in place requiring nonDRIs to mitigate their impacts.

- Developers of DRIs cannot be charged twice to mitigate for the same impacts, as in the case where a local host government charges impact fees. ${ }^{2}$

These research findings established a starting point for developing guidelines for incorporating transit and other multimodal strategies in the DRI review process. Before presenting these guidelines, however, it is important to understand the development of regional impact review process. The following is a basic overview of the statutory basis for the DRI review process, which then focuses on the assessment of impacts to the transportation system, mitigation of those impacts, and the role of the FDOT.

\subsection{Developments of Regional Impact}

Developments of regional impact and the rules regarding them are complex. Although it is not the purpose of this report to describe the process in detail, it is important to establish a few basic facts including where DRIs are addressed in legislation, how they relate to the State Highway System and FDOT's role in the DRI review process.

\section{i. Legislative Basis}

Developments of regional impact (DRIs) are addressed in §380.06, F.S. and are defined as “...any development which, because of its character, magnitude, or location, would have a substantial effect on the health, safety, or welfare of citizens of more than one county" (§380.06(1), F.S.). The primary purpose of the DRI review process is to provide the opportunity for multiple agencies including the applicable regional planning council and affected local governments to identify DRI impacts that cross jurisdictional boundaries and ensure that those impacts are mitigated. Chapter 380, F.S. and Rule 9J-2 of the Florida Administrative Code (F.A.C.) establish requirements and procedures for DRIs, which include:

\footnotetext{
${ }^{2}$ Chapters 380.06(15)(d) and (e) and 380.06(16), F.S.
} 
- criteria for establishing whether a development must undergo DRI review;

- guidelines and standards that implement the criteria and define numerical thresholds for specified different land uses;

- procedures for identifying affected parties;

- the chronological process of DRI review;

- the roles played by various governmental entities;

- the entity notification during each stage of the process;

- time periods for each step of the review process;

- the agencies that are permitted to participate if they choose;

- the circumstances under which an approved DRI requires a new review;

- the circumstances under which changes are made to a developer's vested rights;

- the requirements for public hearings;

- the entity that has final decision authority; and

- the procedures for the appeals process.

The DRI law also establishes the following written instruments, which represent negotiations and agreements throughout the DRI review process:

- a binding letter (optional);

- the preliminary development agreement (optional);

- the pre-application;

- a conceptual agency review (optional);

- the application for development approval (including three sufficiency responses);

- a regional report;

- the development order; and

- monitoring and status reports.

\section{ii. Impacts to the State Highway System}

Rule 9J-2, F.A.C. establishes DRI review procedures including how the Florida Department of Community Affairs (DCA) is to evaluate transportation impacts in the review of applications for binding letters, applications for development approval, and local government development orders. The DCA website ${ }^{3}$ contains information pertinent to the DRI review process including thresholds for review, procedures and forms. One of the forms, the "Application for Development Approval (ADA), Form RPM-BSP-ADA-1" must be completed by the applicant. This form contains 38 questions, each of which concerns a specific topic regarding impacts of the proposed development. Question 21 is a ninepart procedure (A through I) for estimating transportation impacts. Parts A through F constitute a basic traffic impact

ADA Question 21(I)

Transit services, bicycling and

walking are addressed in the

ADA Question 21(I), which asks,

"What provisions, including but

not limited to sidewalks, bicycle

paths, internal shuttles,

ridesharing, and public transit,

will be made for the movement

of people by means other than

private automobile? Refer to

internal design, site planning,

parking provisions, location,

etc."

\footnotetext{
${ }^{3}$ http://www.dca.state.fl.us/fdcp/dcp/Procedures/index.cfm
} 
methodology and parts G through I address site access, protection of transportation corridors, transit service, bicycling, and walking. In addition (Map H) a master development plan must be provided by the applicant. According to the Application, this plan must indicate "proposed land uses and locations, development phasing, major public facilities, utilities, preservation areas, easements, right-of-way, roads, and other significant elements such as transit stops, pedestrian ways, etc.”

DCA relies on FDOT to review the technical aspects of the applicant's response to Question 21 and Map H. Therefore, FDOT staff and consultants must be prepared to review the application for impacts to the existing and planned transportation system. Applicants respond to Question 21 by means of a transportation impact analysis that is prepared in accordance with the procedures outlined in the FDOT "Site Impact Handbook" (1997), ${ }^{4}$ typically prepared by a consultant on behalf of the developer. The "Site Impact Handbook" "was prepared (1) to address mandatory analysis and review requirements, (2) to offer guidance to all agencies on when the Department will be conducting these reviews, and (3) to identify how these reviews will be conducted, including which special practices (i.e., instructions) are applicable for each type of analysis or review." ${ }^{5}$ FDOT staff and others unfamiliar with specific requirements for DRI review should download a copy of the Handbook and become familiar with its contents.

The Handbook defines a site impact as "any effort by the Department to prepare an analysis of or conduct review of an analysis prepared by another party to estimate and quantify the specific transportation-related impacts of a development proposal, regardless of who initiates the development proposal, on the surrounding transportation network. The Department's impact assessment may be limited to the State Highway System (SHS) or on any affected roadway system as determined by the procedures established in the Handbook and the specific type of review being conducted.” 6

The Handbook includes the methodology employed by FDOT in reviewing the transportation impacts of various types of development proposals on the State Highway System. The Handbook also includes detailed procedures, checklists, and criteria for evaluating the potential impacts of comprehensive plan amendments, DRIs, and any developments that request access to state highways as well as guidance and thresholds for a detailed analysis.

The DRI-related transportation impact requirements apply only to transportation facilities of state or regional significance. According to Rule 9J-2.045, F.A.C., roadways considered to be state or regionally significant must be paved and have one or more of the following characteristics:

- cross local government jurisdictional boundaries;

- be a component of the State Highway System (including SIS and/or FIHS);

- connect components of the State Highway System;

- provide access to a regional center; or

- be a hurricane evacuation route.

\footnotetext{
${ }^{4}$ To access a complete version of the "Site Impact Handbook", visit the FDOT Planning Pages website: http://www.dot.state.fl.us/Planning/systems/sm/siteimp/PDFs/site.pdf)

5 “Site Impact Handbook”. Florida Department of Transportation, 1997, page 1.

${ }^{6}$ Ibid.
} 
A state or regionally significant roadway segment is considered to be "significantly impacted by the proposed development if, at a minimum, the traffic projected to be generated at the end of any stage or phase of the proposed development, cumulatively with previous stages or phases, will utilize five percent or more of the adopted peak hour level of service maximum service volume of the roadway, pursuant to [the applicable level of service standard], and the roadway is projected to be operating below the adopted level of service standard at buildout of that stage or phase" (Rule 9J-2.045(6), F.A.C.). If a more stringent transportation facility significant impact threshold is adopted by a local government comprehensive plan, then this significant impact threshold must be used to establish the impact area.

Rule 9J-2.045(7)(d), F.A.C. states, "Where the transportation impacts of the development are determined to occur in more than one local government jurisdiction, the development order shall ensure that any significant multi-jurisdictional facility impacts are mitigated pursuant to the requirements of Section 380.06, F.S., and the applicable level of service standards of the jurisdiction in which the impacts occur.” The FDOT review must include a comparison of the transportation impact analysis presented in the DRI application for development approval with adopted LOS standards in the local government's concurrency management system (CMS), assuming that the standards are in compliance with Rule 14-94, F.A.C.

\section{iii. Mitigation of Impacts}

Mitigation is required at each stage or phase of a project where the transportation impact analysis shows that project traffic consumes more than five percent of a regionally significant roadway's maximum service volume per the adopted LOS standard and will reduce roadway's level of service below the adopted LOS standard (an adverse impact). Strategies to mitigate such impacts can either increase the capacity of a transportation facility or reduce the number of motor vehicle trips generated by the proposed DRI.

The measures to mitigate transportation impacts of a DRI as identified in Rule 9J-2.045(7)(a), F.A.C include:

1. facility improvement scheduling;

2. alternative concurrency provisions;

3. proportionate share payments for roadway improvements based upon peak hour roadway trips generated;

4. level of service monitoring with binding commitments for needed improvements; and,

5. a combination of the above mitigation measures, OR the provision for capital facilities for mass transportation, OR the provision for programs that provide alternatives to single occupancy vehicle travel.

Such mitigation measures or strategies reasonably assure that transportation facilities will be constructed and made available when needed to accommodate the impacts of the proposed development, in a manner consistent with §163 and §380, F.S.

In many cases, significant and adverse transportation impacts are addressed through phasing and pipelining. For transportation, no DRI project phase may be more than five years in length. Often transportation impacts and mitigation strategies are tied to the phases in which a development is built. Pipelining is the practice whereby an improvement is identified as being significant to the transportation system and, rather than making several smaller improvements, 
funds are pipelined or targeted to make a specific improvement. This practice is permitted in accordance with §163.3180(12)(c), F.S. and Rule 9J-2.045(7)(a)(3)(d)(III), F.A.C.

\section{iv. Opportunities for FDOT Input}

Regional planning councils (RPCs) coordinate the DRI review that culminates in a development order containing conditions for mitigating the development's impact on regional facilities including transportation. FDOT staff review and comment on DRIs in accordance with guidance found in the FDOT "Site Impact Handbook" which refers to the DRI review process as "the most formal and complex review requirements imposed upon the Department." The Handbook outlines the DRI review process and

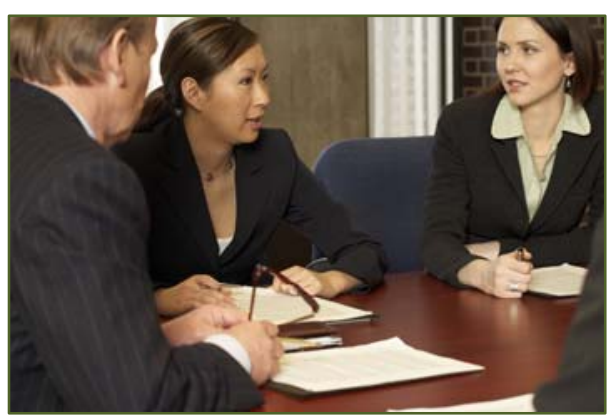
highlights the following points where FDOT reviewers play a role:

- Pre-application Conference Format Meeting;

- Pre-application Conference Project Summary Narrative Review;

- Transportation Methodology Meeting Information Submittal Review;

- Review of RPC Regional Issues List and Agency Comments (which may include Transportation Methodology Letter of Understanding);

- Application for Development Approval (ADA) Review;

- ADA Sufficiency Review;

- Local Government Development Order Review;

- Annual Report Review; and

- Notice of Proposed Change.

The guidelines in this document build on the review structure contained in the "Site Impact Handbook" which relies primarily on a checklist format. The Handbook currently contains the following checklists to assist FDOT staff and consultants with DRI review:

1. Transportation Methodology Meeting Information Submittal Checklist;

2. DRI-ADA Sufficiency Review Checklist;

3. DRI-ADA Review Checklist;

4. Local Government Development Order Review Checklist;

5. Project Monitoring Report Review Checklist;

6. Conceptual Agency (Access) Review Checklist; and

7. Notice of Proposed Changes/Substantial Deviation Determination Notification Checklist.

\subsection{Performance Measures}

This report also offers performance measures to track the effectiveness of the recommended guidelines. Performance measures provide indicators of progress toward the completion of an objective or objectives to accomplish a goal. Because they can steer the actions taken to complete an objective (i.e., what gets measured is what gets accomplished), measures must be carefully selected. Performance measures may be applied to evaluate a process, on-going long-range 
planning, or a particular program with a discrete end time and may also reflect priorities established through a political process. To measure performance, baseline conditions must be established to determine a starting point followed by a means to track progress. The ability to use performance measures is often tied to the availability of appropriate data and analysis methods. Because it takes time, effort, and resources to monitor performance, actual measures should be limited to the most useful measures.

The recommended guidelines throughout this document are accompanied by corresponding performance measures, in accordance with the FDOT Business Model. These indicators are intended to gauge the degree and quality of FDOT staff involvement in the DRI review process. The ultimate goal of this document is the incorporation of transit and other multimodal strategies into new development, particularly DRIs.

\subsection{Challenges to Incorporating Multimodal Strategies}

Location. DRI's are predominately located in the suburbs where no bus or rail facilities currently exist.

Exacerbating the situation is the fact that the DRI is likely being considered as a comprehensive plan amendment concurrent with its DRI application. This makes it unlikely that any multimodal facilities have

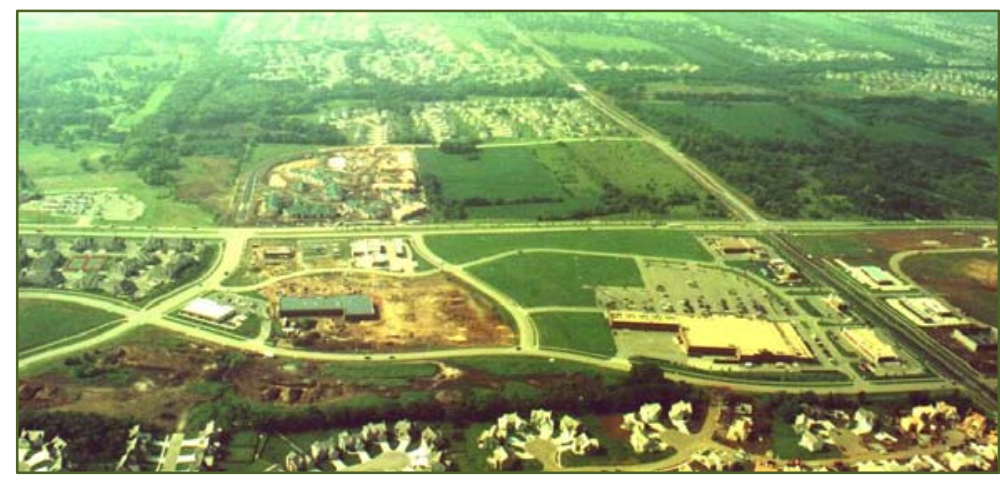
been planned for the area. Most local governments are not equipped to evaluate the cumulative effect of proposed large-scale developments on the transportation element of their comprehensive plan or transit development plans. The lack of specifically-identified transit service results in developers' unwillingness to include bus stop improvements or transit stations in proposed developments. In many cases, developers will include bicycle paths, trails, and sidewalks within new developments; however, such efforts do little to decrease vehicular impact on roadways serving those developments.

Number of trips. A transportation impact assessment examines the number of new trips generated by a proposed development and the cost of mitigating any adverse impacts caused by those new trips. Because neither development configurations nor new transit service result in a measurable number of trips being taken off the road, review agencies allow only a minimal mode split. Consequently, mitigation often takes the form of roadway improvements. A unified vision for multimodal projects that is codified in the local government comprehensive plans and land development regulations will encourage expenditures on alternative mitigation.

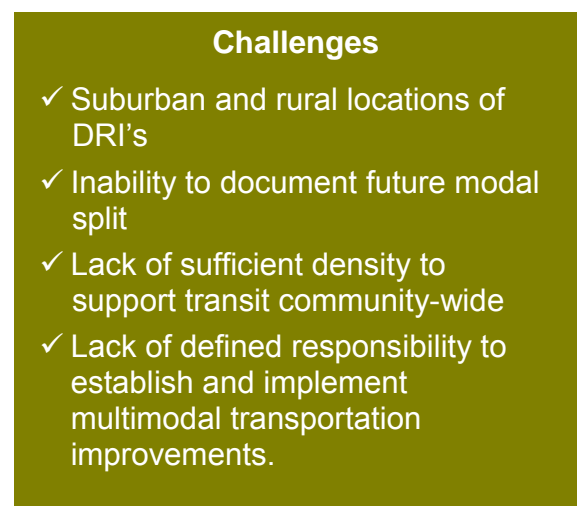

A related issue is that of reviewer expertise. Most transportation reviewers whether FDOT staff or consultants are traffic specialists. FDOT Public Transit Office staff and/or consultants with transit 
expertise should participate in the DRI review process to review the technical aspects of any transit components as well as to facilitate coordination with applicable transit agencies. Likewise, transit agencies should take advantage of the opportunity to review and comment on proposed DRIs as well as work with the developer and other reviewers on multimodal mitigation strategies.

Separation of land uses. In recent years, many developers in Florida have proposed traditional neighborhood development, transit-oriented development, and other similar development styles. In general, these development styles are used as sales mechanisms and also to suggest that such development would generate fewer automobile trips. These development styles placed within Florida's existing development patterns cannot achieve dramatic reductions in regional automobile trips. The spread between jobs, housing, affordable housing, retail, and services is too great to be minimized by sporadic, though carefully planned new development. Communities must strive to establish fixed transit corridors and focus development along those corridors with adequate density and intensity to make transit use feasible. The establishment of such corridors will require the unified vision and resources of many agencies along with the development community.

Responsibility. Perhaps the greatest challenge is that of responsibility. The DRI application includes the requirement to address multimodal systems; however such requirements have historically received little attention from applicants and reviewers. This research revealed that most reviewers are unclear regarding who is responsible for the incorporation of multimodal strategies into the DRI review process.

Local government involvement is critical to establishing a multimodal vision; however, elected officials, staff, and the general public must be equipped with knowledge and assisted with technical expertise. Ideally, FDOT, MPOs, regional planning councils, counties, municipalities, and transit agencies can work together to develop a comprehensive multimodal plan that developers can integrate into their projects regardless of the size. As the coordinator of DRI reviews, RPCs may be the logical leader in addressing multimodal issues. Section 4 of this report addresses methods to help this effort including education and training, relationship building, and a multimodal peer exchange. 


\section{Multimodal Policy}

The recommended guidelines presented in the remainder of this report are designed to assist both the developer and reviewer in assessing proposed developments for a comprehensive multimodal approach to transportation between the development and the surrounding community. They will be incorporated into the FDOT "Site Impact Handbook" along with any future updates. The guidelines address policy language, project tracking, information for applicants, methodology for addressing alternative modes of transportation, mitigation strategies, and sample comment language. While a single application may not shift travel behavior, a consistent system-wide approach can result in a multimodal transportation system for urban communities and a decrease in the growth rate of vehicle miles traveled.

\subsection{Model Multimodal Policy Direction}

Over the past several years, directives from state-level long range transportation planning, changes to the State's growth management legislation, and FDOT internal efforts to improve organizational performance and accountability have converged to place increased emphasis on multimodal approaches for improving regional mobility. The State of Florida planning framework points to transit as part of the solution to meeting future mobility needs.
FDOT Planning Themes Related to DRI Review

Alternatives to SOV travel

Regional coordination

Multimodal approach

Economic development

Coordination with private partners

Regional transit service

Many DRI reviews are conducted by FDOT staff and consultants who have been involved with the process for many years. The Department's review is focused on the DRI's transportation impact analysis pertaining to the State Highway System as outlined in the FDOT "Site Impact Handbook.” Historically, guidance for FDOT review of DRIs has been to minimize traffic congestion and delay on FDOT highway facilities by maintaining LOS standards on significantly impacted regional transportation facilities.

This focus on maintaining highway level of service has resulted in mitigation strategies largely designed to increase highway capacity through roadway widening and/or attention to specific trouble spots. The focus on highway impacts and mitigation measures illustrates the lack of explicit or implicit guidelines, policies or procedures for incorporating transit and other multimodal strategies within DRIs. The state of Florida planning framework, established through the 2025 State of Florida Transportation Plan, Strategic Intermodal System Plan, and Transit 2020 Plan, advocates a multimodal approach to meeting future mobility needs. Adoption of a clearly articulated policy at the state level will convey the state's multimodal intent to FDOT District staff and consultants involved in DRI reviews. The desired result is consistent incorporation of transit and other multimodal strategies in DRIs. Below is a recommended policy statement that may be considered at a state level.

Model Policy:

\section{ALTERNATIVE MODES IN THE DEVELOPMENT OF REGIONAL IMPACT REVIEW PROCESS}

The purpose of this policy is to ensure that the Florida Department of Transportation (Department) considers alternative modes of transportation during the review of all developments of regional impact. Alternative modes of transportation include all 
modes other than single occupancy vehicles (SOV) including rail and bus transit, transportation demand management strategies, bicycling, and walking.

The Department recognizes the impact of such large scale development on the State Transportation System and the benefit of ensuring that a variety of travel options are available not only within the development, but between the development and the surrounding community or regional system. Such travel options rely on mode as well as system connectivity. The Department will encourage and promote the incorporation of alternative modes throughout the DRI review process. 


\section{INSTRUCTIONS FOR MULTIMODAL DRI REVIEW}

The developer of a proposed DRI is required to prepare an Application for Development Approval ${ }^{7}$ (ADA) in accordance with DRI requirements as agreed upon during the preapplication conference and the transportation impact methodology meeting. The application is designed to provide reviewers with a comprehensive understanding of the proposed development details. Reviewers from affected local governments and other agencies are then to provide comments and recommendations that the regional planning council compiles into a final report and recommendation to the local government with jurisdiction over the proposed DRI.

The ADA consists of 38 questions, each concerning a specific topic. Question 21 of the ADA is a nine-part question (Part A through Part I) that outlines the procedure for estimating the transportation impacts of a DRI (see Appendix B). Map J, an application requirement, is "a map of the existing highway and transportation network within the study area. The study area includes the site, and location of all transportation facilities which are substantially impacted. This area should be finally defined on the basis of the findings of the traffic impact analysis, including determinations of where the criteria for a substantial impact are met. Map J will become the base for the maps requested in Question 21.”

Transit services, bicycling, and walking are specifically addressed in the ADA Question 21(I), which asks, "What provisions, including but not limited to sidewalks, bicycle paths, internal shuttles, ridesharing, and public transit, will be made for the movement of people by means other than private automobile? Refer to internal design, site planning, parking provisions, location, etc." However, this does not preclude other modes from being addressed in the entirety of the response to Question 21. For example, Question 21(A) addresses level of service which should include an applicable LOS analysis for non-vehicular modes. Question 21(B) requires that the modal split be addressed. In addition, the master development plan, Map H, contains planned land use and transportation facilities vital to analyzing project impacts.

As such, each DRI application should include ample details regarding existing and planned multimodal features of the transportation system, as well as how the DRI will interact with and enhance the system. Specifically, the ADA should include information provided by the applicant regarding multimodal access and interconnection between the DRI and the surrounding community. Thresholds for multimodal features, if available, can be found in local government plans or regulations. Such an analysis will increase the awareness of both the developer and reviewer regarding how the proposed development can incorporate and enhance the existing transportation system. For example, bicycle and pedestrian access to transit are essential to support transit use. A development may have a person living within 200 feet of a bus stop; however, that person may have a one-mile walk to get outside of the subdivision wall to access the bus stop. A detailed multimodal analysis will reveal such access issues and open the door to possible solutions.

\footnotetext{
${ }^{7}$ Available on the DCA website http://www.dca.state.fl.us/fdcp/dcp/Procedures/index.cfm
} 
Incorporation of multimodal considerations into the DRI review process should occur at each stage of the review process (see inset). This section adheres to the format of Unit IV, Chapter 1 - Instructions for DRI Reviews in the FDOT "Site Impact Handbook". Reviewers should consider this information as supplemental to the Handbook as well as Florida statutes, administrative codes and DRI guidelines from the Florida Department of Community Affairs.

Research for this project revealed that applicants, often previously involved in some aspect of a DRI, are generally quite familiar with the DRI review process, particularly application for development approval submission requirements. Such familiarity is a factor in the continued use of conventional mitigation strategies for transportation-related impacts which focus on infrastructure improvements to accommodate single occupant vehicle travel, rather than multimodal solutions. Failure to fully address the multimodal transportation system within the ADA itself may be attributed somewhat to outdated requirements reflected in the "Site Impact Handbook". As transportation professionals, it is incumbent on FDOT, along with other transportation partners, to emphasize a multimodal transportation system and to provide applicants with appropriate resources and technical assistance to address both existing and planned systems.

DRI applicants and reviewers including FDOT staff and consultant DRI reviewers have historically focused on impacts to State Highway System facilities identified as significantly impacted by DRI project traffic. As such, District Public Transit Office (PTO) staff has not been involved in the DRI review process. Implementation of concepts in this report may necessitate District PTO staff involvement throughout the DRI review process. Review checklists in the FDOT "Site Impact Handbook" along with multimodal supplements contained in this report will assist them in addressing pertinent aspects of the review. These checklists are not intended to be all-inclusive in that they do not offer specific parameters or limits for each the items listed. Rather, the reviewer is provided with a reminder of the different aspects of the development application to address in the DRI review comments. Development parameters, if available, can be found in local plans and regulations.

\subsection{Preapplication Conference Format Meeting and Information for Applicant}

FDOT’s “Site Impact Handbook” identifies the Department reviewer’s role regarding the preapplication conference format and information for the applicant as follows:

- To establish whether or not the Transportation Methodology Meeting is to be conducted as part of the Preapplication Conference; and,

- To identify the information the applicant is requested to submit for review prior to the Transportation Methodology Meeting.

The Handbook recommends that applicants be provided with a list of available resources along with the review checklist entitled, "Information Provided/Availability Made Known to Applicant Checklist” (Information Checklist) (Table 26 on page 115 of the Handbook ${ }^{8}$ ). This checklist offers

\footnotetext{
8 “Site Impact Handbook”. Florida Department of Transportation, 1997, page 115, Table 26.
} 
a number of specific resources as well as some general guidance for other information. The checklist provided in the Handbook includes two specific resources directly related to transportation modes other than personal or service vehicles, the Bicycle Facilities Planning and Design, and the Florida Pedestrian Safety Plan.

In addition, the checklist suggests that other information offered to the applicant include "resources for obtaining Department guidance on such mitigative techniques as public transportation and programs providing alternatives to single-occupant vehicle travel." Since the Handbook was initially written, many multimodal-related resources have been developed providing a wealth of information regarding the use of alternatives to the single-occupant vehicle. As such, it is essential that such information be readily available to the development community.

It is recommended that FDOT staff provide each developer/applicant with up-to-date information and resources regarding the existing transportation system, particularly multimodal elements. Table 1, a supplement to the Information Checklist, contains multimodal resources currently available throughout the state. Internet links to document-specific resources are included and could be easily accessed by applicants if posted on a centralized web location for each District. The resources are described in detail in Appendix C. FDOT District staff should expand on this supplemental list to include all applicable locally-specific resources.

Development ideas and concepts occur long before the applicant makes initial contact with the permitting local government, thereby making it essential that developers are informed of multimodal concepts at the earliest opportunity. It is important to make these resources readily available to ensure that developers are familiar with existing public transportation and commuter assistance programs and services as well as future multimodal plans. This information, provided prior to or during the pre-application meeting, will assist the applicant in the preparation of appropriate in-depth multimodal responses to the ADA. In addition, FDOT staff and consultant reviewers should have copies of and training on the relevant documents to use as references when reviewing DRI applications. 
TABLE 1 Information Provided/Available to Applicant Checklist - Multimodal Supplement

Information Provided/Availability Made Known to Applicant - Multimodal Supplement

MPO Long Range Transportation Plan (LRTP) (as applicable)

Transit Development Plan (as applicable)

Transportation Disadvantaged Service Plan (or other locally developed, coordinated public transit-human services transportation plan as required by the Jobs Access and Reverse Commute (JARC) and New Freedom Programs) (as applicable)

Local Government Comprehensive Plans (LGCP) (as applicable)

FDOT's Quality/Level of Service Handbook, 2007 LOS Issue Papers and accompanying software

Link: http://www.dot.state.fl.us/planning/systems/sm/los/los sw2.htm

Multimodal Transportation Districts and Areawide Quality of Service Handbook (November 2003)

Link: http://www.dot.state.fl.us/planning/systems/sm/los/pdfs/MMTDQOS.pdf

Transportation Demand Management Resources

Link: http://www.nctr.usf.edu/clearinghouse/

Commuter Assistance Programs (as applicable)

Design Manuals (as applicable)

- Accessing Transit Design Handbook for Florida Bus Passenger Facilities (statewide)

Link: http://www.dot.state.fl.us/transit/Pages/AccessingTransitHandbookLow.pdf

- LYNX Central Florida Mobility Design Manual

Link: http://www.golynx.com/assets/userfiles/media/pdf/lynxdocs mobility manual.pdf

- LYNX Central Florida Customer Amenities Manual

Link: http://www.golynx.com/assets/userfiles/media/pdf/lynxdocs Amenities Manual.pdf

- FDOT District I and 7 Transit Facility Handbook

Link: http://www.dot.state.fl.us/Transit/Pages/FDOT D1 D7 Transit Facility Handbook.pdf

- FDOT District 4 Transit Facilities Guidelines

Link: http://www.dot.state.fl.us/transit/Pages/UpdatedD4TransitFacilitiesGuidelines.pdf

- Palm Tran Transit Design Manual

Link: http://www.pbcgov.com/palmtran/marketing/pdf/library/transit-design-manual.pdf

- Jacksonville Transportation Authority Mobility Access Program Handbook Link: http://www.jtaonthemove.com/workwithus/pdf/AccessProgram.pdf?SUBMIT=go

- Incorporating TDM into the Land Development Process Link: http://www.nctr.usf.edu/pdf/576-11.pdf

- Land Developer Participation in Providing for Bus Transit Facilities/Operations Link: http://www.nctr.usf.edu/pdf/Land\%20Developer.pdf

- Leadership in Energy and Environmental Design (LEED) Certification Link: http://www.usgbc.org/DisplayPage.aspx?CategorylD=19

- Model Regulations and Plan Amendments for Multimodal Transportation Districts (MMTDs) Link: http://www.dot.state.fl.us/planning/systems/sm/los/pdfs/MMTDregs.pdf

Additional resources from FDOT research on multimodal LOS analysis:

Link: http://www.dot.state.fl.us/planning/systems/sm/los/default.htm

Other related local and regional plans 


\subsection{Transportation Methodology Meeting}

The "Site Impact Handbook" calls the transportation methodology meeting "a pivotal point in the DRI process" where FDOT reviewers have the ability to express their concerns regarding the proposed DRIs impact on the State Highway System. Both applicants and reviewers stress the importance of this meeting as the time to be very clear about what information related to transportation must be included in the DRI application.

To make each applicant fully aware of the type of multimodal features that reviewers will be seeking in the application, it is recommended that the reviewer provide Table 2 to the applicant. Table 2 specifies information to be provided by the applicant to address modes other than singleoccupant vehicles. Detailed parameters may be found within the Resources listed in Table 1 that are provided to the applicant. This information is subject to local conditions and not conducive to statewide parameters.

TABLE 2 Multimodal Information to be Included in the ADA

\begin{tabular}{|c|c|}
\hline \multicolumn{2}{|l|}{ Multimodal Information to be Included in the ADA } \\
\hline \multicolumn{2}{|l|}{ DRI Study Area - Document existing conditions } \\
\hline 1. High-occupancy vehicle lanes - availability, location, and usage & \\
\hline $\begin{array}{l}\text { 2. Transit service (rail and/or bus) - availability, location, level of service, } \\
\text { duration, frequency, connectivity, and ridership. Also note if services are } \\
\text { limited to certain populations such as the elderly or disabled }\end{array}$ & \\
\hline 3. Bus rapid transit - availability, location, level of service, and ridership & \\
\hline $\begin{array}{l}\text { 4. Multi-use trails, local and regional (off-road) - availability, location, standard of } \\
\text { facility design, LOS, connectivity, parking locations, and usage }\end{array}$ & \\
\hline $\begin{array}{l}\text { 5. Bicycle lanes (on-road) - availability, location, standard of facility design, } \\
\text { LOS, connectivity, usage and bicycle facility sweeping and maintenance }\end{array}$ & \\
\hline $\begin{array}{l}\text { 6. Sidewalks/pedestrian facilities - availability, location, standard of facility } \\
\text { design, LOS, connectivity and usage }\end{array}$ & \\
\hline 7. $\quad$ Parking management & \\
\hline $\begin{array}{l}\text { 8. Transportation demand management - Commuter assistance services (i.e., } \\
\text { vanpools, guaranteed ride home) - availability and usage. See transportation } \\
\text { demand management (TDM) resources }\end{array}$ & \\
\hline 9. Broadband/wireless - availability (to allow telework, teleconferencing, etc.) & \\
\hline 10. Baseline modal split of alternative modes & \\
\hline $\begin{array}{l}\text { 11. Planned, programmed or committed improvements to existing or new } \\
\text { multimodal facilities including documentation of designated corridor space for } \\
\text { transit or multimodal options }\end{array}$ & \\
\hline $\begin{array}{l}\text { 12. The existing level of service for transit or multimodal alternatives, if the local } \\
\text { government or transit agency has adopted such LOS standards }\end{array}$ & \\
\hline \multicolumn{2}{|c|}{$\begin{array}{l}\text { Land Use/Site Design - Discuss how development is consistent with local government comprehensive plans, } \\
\text { land development regulations, special area plans, or other applicable mechanisms. For multimodal purposes, the } \\
\text { information should include the following: }\end{array}$} \\
\hline 1. Variety of land uses, including both employment and residential & \\
\hline 2. Land uses that promote pedestrian, bicycle, and transit use & \\
\hline 3. Sufficient densities to support transit ridership & \\
\hline 4. Sufficient intensity along major transit corridors & \\
\hline 5. Sufficient intensities in and around core areas & \\
\hline $\begin{array}{l}\text { 6. Connectivity to adjacent properties, surrounding communities, and the } \\
\text { surrounding street network; include multimodal connectivity analysis }\end{array}$ & \\
\hline
\end{tabular}




\begin{tabular}{|l|l|}
\hline \multicolumn{2}{|c|}{ Multimodal Information to be Included in the ADA } \\
\hline 7. Appropriate numbers of connections within the street network & \\
\hline 8. Support of pedestrian environment including shorter block lengths, traffic & \\
calming measures, traffic enforcement programs, etc. & $\begin{array}{l}\text { * Many developments restrict parking for vehicles with logos or do not have a public parking space to handle a 15-22 person } \\
\text { van. Allowance for overnight parking for vanpool vans is critical to implementing this TDM strategy. }\end{array}$ \\
\hline
\end{tabular}

The Handbook’s DRI Checklist 1, “Transportation Methodology Meeting Information Submittal Checklist" is designed to "cover issues raised in a typical DRI review." The categories of evaluation criteria included in the checklist include project information, data collection and existing conditions, project approach, trip generation, trip distribution, mode split, trip assignment, analysis procedures, and other considerations. Table 3 comprises the multimodal supplement to DRI Checklist 1.

\section{TABLE 3 DRI Checklist 1. Transportation Methodology Meeting Information Submittal Checklist - Multimodal Supplement}

\begin{tabular}{|l|l|l|l|l|}
\hline \multicolumn{1}{|c|}{ Evaluation Criteria } & Y & N & N/A & Comment \\
\hline Other Considerations & & & & \\
\hline $\begin{array}{l}\text { Add Item F as follows: } \\
\text { F. Is applicant aware of requirement to address multimodal } \\
\text { site access and connectivity? }\end{array}$ & & & \\
\hline
\end{tabular}

In urban and suburban scenarios, applicants often claim that trips from the proposed development will be minimized due to close interaction with the existing community surrounding the DRI. Because system connectivity and access to nearby activity centers is crucial to incorporating the DRI into the community, reviewers may ask the applicant to be very specific about this connectivity. A method for performing a detailed multimodal connectivity analysis is provided in Appendix D.

Specific items required for transportation review include all files and calculations used in traffic modeling. This information is sometimes omitted from the application and not provided despite subsequent requests for the information. FDOT reviewers, the applicable regional planning council, and the permitting local government should be in absolute agreement that a complete application includes this critical data.

DRI Checklist 1 is very general in nature. Trip generation and mode split may warrant a closer look from a multimodal perspective by both applicants and reviewers. The following provides guidance to ensure multimodal considerations are made when establishing trip generation and mode split.

- Trip generation - Provide written justification of the appropriateness and limitations of the trip generation rates used, based upon a comparison of the proposed DRI land development patterns, densities, and parking availability to those of developments used to calculate the trip generation rates. Evaluate the possibility of using locally-derived person trip data by land use or locally-derived vehicular trip generation information for developments of similar composition and location to the proposed DRI. Note that review agencies typically require an applicant to submit a separate methodology statement and review process for a minimum of three sample locations. 
- Mode Split - Applicants are asked to provide documentation supporting a mode split. This documentation may include any identified planned, programmed or committed improvements to transit and other multimodal options. Information may be found in local government comprehensive plans, transit development plans, public transit-human services coordinated transportation plans, or selected area plans. Tools to assist in this effort are also under development. The Transit Boardings Estimation and Simulation Tool $^{9}$ (TBEST) may be used for transit and ridership forecasting. The Conserve by Bicycle model, ${ }^{10}$ currently under development, will determine where energy can be conserved by providing bicycle facilities that reduce the use of motor vehicles in an area.

In cases where conditions are not conducive to transit use (e.g., trip generation rates are suitably comparable, the proposed land development is not a transit oriented development, and parking is abundant and free), the applicant should identify local targets and timelines for increasing transit modal split in the vicinity of the study area. Because mode split is dependent on household income and car ownership, documentation of these factors should also be provided. Local transit development plans or comprehensive operations analyses may include information helpful in determining mode split.

Because the transportation impact assessment, particularly travel demand modeling, does not take into account trips that occur within the same traffic analysis zone or short trips between zones on local roads or multimodal paths, it is important to address these trips separately, particularly if the applicant stresses that the development is designed to encourage the use of other modes. A welldeveloped multimodal local street system provides travelers alternatives to the regional transportation system.

In many cases, the applicant is required to submit the proposed transportation methodology in advance. This gives the reviewers the opportunity to provide early comment on the details of the proposed methodology. One example of such comments is provided in Appendix E. The example is from District 4 in which the applicant requests trip reductions based on multimodal use. The comments offer a conditional acceptance of the reductions based on additional information to be provided by the applicant.

\subsection{RPC Regional Issues List and Agency Comments}

The FDOT "Site Impact Handbook" describes this part of the DRI review process as the point where "the RPC summarizes the results of ... [the preapplication conference and the transportation methodology] meetings, in writing, to the applicant." This is referred to as the "Transportation Methodology Meeting Letter of Understanding” in later portions of the review process. The

\footnotetext{
${ }^{9}$ TBEST is a comprehensive transit analysis and ridership forecasting model that is capable of simulating travel demand at the individual stop-level while accounting for network connectivity, spatial and temporal accessibility, time-of-day variations, and route competition and complementarity. More information is available at http://www.tbest.org

${ }^{10}$ The Conserve by Bicycle Program (Section 335.07, F.S.) purposes include reducing traffic congestion on existing roads and increasing efficiency of cycling as a transportation mode by improving interconnectivity of roadways, transit and bicycle facilities. FDOT has commissioned a study to produce a model for determining where energy can be conserved by providing bicycle facilities that reduce the use of motor vehicles in an area.
} 
Handbook strongly encourages the Department reviewer to request the opportunity to review the information prepared by the RPC before it is sent to the applicant. Research for this project did not find the Department's review of the meeting summary to be a common practice; however, researchers agree with the importance of ensuring that the meeting summary, particularly details of the transportation impact methodology, is truly reflective of agreements made during the meeting. The Handbook refers the reviewer back to DRI Checklist 1 to complete this review.

\subsection{Sufficiency Review}

The sufficiency review provides the reviewer an opportunity to determine if the applicant has provided sufficient information in the application for development approval regarding the proposed DRI and its impacts within the DRI application. The "Site Impact Handbook" highlights the following areas of concern for the reviewer regarding the ADA:

1. adheres to the conditions set forth in the Transportation Methodology Meeting Letter of Understanding;

2. provides sufficient detail and support documentation to enable the Department reviewer to adequately assess project impacts on the SHS; and,

3. proposes impact mitigation measures which adequately protect LOS on SHS/FIHS facilities.

It is important that the reviewer use this opportunity to comment regarding any deficiencies in the ADA. Table 4 is the multimodal supplement to the DRI Checklist 2, "DRI-ADA Sufficiency Review Checklist." The reviewer should keep in mind the multimodal requirements for the application for development approval that are detailed in DRI ADA Checklist.

TABLE 4 DRI Checklist 2. DRI-ADA Sufficiency Checklist - Multimodal Supplement

\begin{tabular}{|c|c|c|c|c|}
\hline Evaluation Criteria & Y & $\mathbf{N}$ & N/A & Comment \\
\hline $\begin{array}{l}\text { Revise Section A as follows: } \\
\text { Section A. Adequate explanation of existing conditions, data } \\
\text { collection, and analysis procedures for all transportation } \\
\text { modes for Section A review? }\end{array}$ & & & & \\
\hline $\begin{array}{l}\text { Revise Section B as follows: } \\
\text { Section B. Adequate discussion of trip generation data, } \\
\text { modal split, assumptions, and methods from a multimodal } \\
\text { perspective provided for Section B review? }\end{array}$ & & & & \\
\hline $\begin{array}{l}\text { Revise Section G as follows: } \\
\text { Section G. Adequate discussion and graphics describing } \\
\text { internal project traffic circulation, network connectivity, and } \\
\text { access strategies for Section G review? }\end{array}$ & & & & \\
\hline $\begin{array}{l}\text { Revise Section } \mathrm{H} \text { as follows: } \\
\text { Section } \mathrm{H} \text {. Adequate discussion of project's contribution to } \\
\text { planned transportation corridors, regardless of mode, as } \\
\text { shown in local plans through protection and/or development } \\
\text { for Section H review? }\end{array}$ & & & & \\
\hline
\end{tabular}




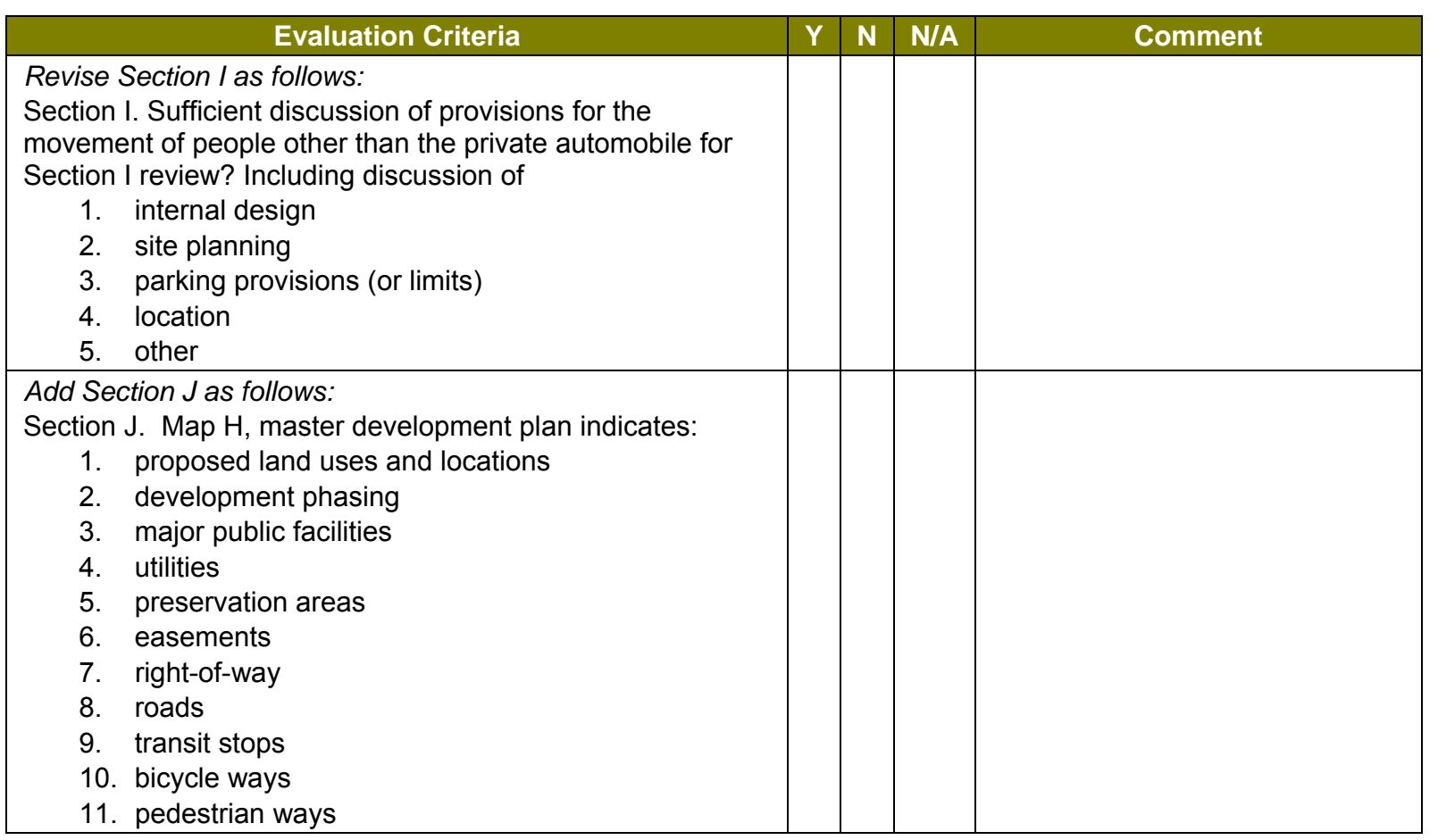

FDOT District staff should provide thorough comments regarding whether or not the information provided in the ADA is sufficient to analyze project impacts on the transportation system. This includes multimodal concerns such as existing conditions, trip generation, land use and site design, and modal facilities among others. There is no specific guidance in the "Site Impact Handbook" regarding the form of such comments. Because the most useful information comes from practitioners, the following comments taken verbatim from sufficiency review letters may serve as guidance. In addition, District 4 uses a compilation of ADA review comments taken from several DRI developments and grouped by category as guidance for developing comments (See Appendix F).

- Orchard Park DRI ${ }^{11}$

1. The coordination of land uses with adjacent uses is not apparent since the surrounding uses are not included on Map $\mathrm{H}$ or other maps in the ADA. Coordination of land uses as well as internal street connectivity are important provisions in order to make progress towards providing traveler choices other than by single occupant vehicles.

2. In order to foster desirable characteristics that result in sustainable development, including access to various modes of travel to and from adjacent land uses, the DRI applicant should be required to develop design guidelines that demonstrate how urban design, land use, and roadway characteristics will result in optimal mobility for the project and beyond.

3. The DRI claims to be encouraging non-vehicular forms of travel. However, no maps are provided which demonstrate the accessibility of land uses to bicycles,

\footnotetext{
11 “Orchard Park (formerly West St. Lucie Farms) ADA-OMD Comments,” Florida Department of Transportation, District 4 Office of Modal Development, Ft. Lauderdale, October 2005, unpublished data.
} 
pedestrians, and future transit facilities. The applicant should consider providing a transportation map for the DRI that overlays the vehicular, bicycle, pedestrian, and transit facilities and services that are expected to serve the DRI. Key parking areas and parking strategies should also be identified to aid in assessing how this infrastructure affects the encouragement of alternative modes of travel. The ADA indicates bicycle facilities will be provided to connect to other greenways. It is important that bicycle and pedestrian facilities be created throughout the area to foster forms of mobility other than the single-occupant vehicle. The project will not be marketed as retiree or second homes, and nearby and on-site research and development employment opportunities will abound. As such, the project will draw families with children to the community and therefore bicycle and pedestrian access between residential areas, commercial areas, and community facilities, such as parks and schools, should be included with the development.

4. Many of the previous comments also relate to making the community "Transit Ready.” The application proposes clustered development with residential densities of nine to fifteen units per acre. These densities are sufficient to support fixed route transit service and should be located on Map $\mathrm{H}$ of the ADA as well as the transportation map requested above. Although transit does not service the area at this time, the application should not only make a commitment to accommodate future service but also to maximize it through supportive land uses, urban design, and connectivity. The demand between the research and development uses to the north and the commercial/mixed use areas along SR-70 will also support transit service. The applicant should coordinate with the St. Lucie Council on Aging to discuss the potential for future extension of existing transit service on Okeechobee Road from east of the Turnpike to the development. Such discussion should also be documented and reported as part of the ADA.

5. Local governments must adopt the LOS standards set by the Department for Strategic Intermodal System (SIS) facilities. As such, the applicant and County will need to ensure the level of service set for State Road 70/Okeechobee Road is not exceeded. Consideration should be given to increasing the grid pattern of local and regional roads to provide alternate routes. To address potential congestion, the applicant also could commit to the development and implementation of transportation demand management strategies to reduce project related peak hour automobile trips. The applicant might consider integrating a park and ride lot with the commercial development along SR-70. This will enable commuters to accommodate various trip purposes from one location and will thus reduce vehicles miles traveled and impacts to area roadways, including the SIS.

6. Much of the above information is necessary to enable the Department to conduct a thorough review of the DRI for Question 21(I) of the ADA. The information will also aid in the review of anticipated comprehensive plan amendments for consistency with the following County policies:

- establish bicycle and pedestrian facilities;

- ensure sidewalk connectivity and completion of missing sidewalk segments;

- review all future development plans for compatibility with transit; and, - identify areas with a high probability for being served by transit. 


\subsection{Application for Development Approval (ADA) Reviews}

The "Site Impact Handbook" concludes that "the DRI-ADA submittal and subsequent review by the Department represent the crux of the DRI review process. It constitutes the first and most comprehensive opportunity for the Department Reviewer to communicate Department concerns to other review agencies and the applicant regarding the transportation impacts caused by the development.” The Handbook includes DRI Checklist 3: DRI-ADA Review Checklist to assist the reviewer which "has been prepared to correspond to the format of Question 21,"and"focuses on the substance of the applicant's responses.” The Handbook also urges reviewers to seek assistance in performing the review if they find it outside their technical ability.

DRI Checklist 3, "DRI-ADA Review Checklist” is the most lengthy of the DRI checklists. The checklist is modeled from DRI Question 21 and provides the reviewer with many reminders of items to look for in the ADA but does not include specific multimodal concerns. Table 5 constitutes a supplemental checklist for the reviewer. Elements of the checklist pertaining to sufficient densities and intensities to support transit refer the reviewer to applicable local or regional regulatory mechanisms for specific parameters; however, if these parameters are not available, the applicant should be asked to justify proposed densities and intensities if transit is a proposed

The "Site Impact

Handbook" stresses the

importance of compliance with review deadlines.

"The ADA review period

is 30 calendar days. A

comment by the

Department after the

legal deadline 30

calendar days, which

starts from the RPC's

receipt of the ADA, can

technically be ignored by

the applicant." mode of accommodating person trips generated by the DRI.

TABLE 5 DRI Checklist 3. DRI-ADA Review Checklist - Multimodal Supplement

\begin{tabular}{|c|c|c|c|}
\hline Evaluation Criteria & $\mathbf{N}$ & N/A & Comment \\
\hline \multicolumn{4}{|l|}{$\begin{array}{l}\text { Revise Section A as follows: } \\
\text { Section A: Existing Conditions }\end{array}$} \\
\hline $\begin{array}{l}\text { 1. Within an existing transportation concurrency exception } \\
\text { area (TCEA), transportation concurrency management } \\
\text { area (TCMA), or multimodal transportation district } \\
\text { (MMTD) and complies with local government } \\
\text { requirements }\end{array}$ & & & \\
\hline $\begin{array}{l}\text { 2. High-occupancy vehicle lanes - availability, location, } \\
\text { and usage }\end{array}$ & & & \\
\hline $\begin{array}{l}\text { 3. Pricing strategies - transit subsidies, parking fees, } \\
\text { parking discounts for ride sharers, parking cash out, } \\
\text { travel allowances, tax benefits }\end{array}$ & & & \\
\hline $\begin{array}{l}\text { Transit service - location, level of service, span of } \\
\text { service, frequency, coverage, connectivity, loading } \\
\text { reliability, ridership, and transit auto travel time ratio }\end{array}$ & & & \\
\hline $\begin{array}{l}\text { 5. Bus rapid transit - location, level of service, span of } \\
\text { service, frequency, coverage, connectivity, loading, } \\
\text { reliability, ridership, and transit/auto travel time ratio }\end{array}$ & & & \\
\hline $\begin{array}{l}\text { 6. Multi-use trails, local and regional (off-road) - } \\
\text { availability, location, standard of facility design, LOS, } \\
\text { connectivity, parking, and usage }\end{array}$ & & & \\
\hline $\begin{array}{l}\text { 7. Bicycle lanes (on-road) - availability, location, standard } \\
\text { of facility design, LOS, connectivity, usage, and } \\
\text { connectivity to transit }\end{array}$ & & & \\
\hline 8. Sidewalks/pedestrian facilities - availability, location, & & & \\
\hline
\end{tabular}




\begin{tabular}{|c|c|c|c|c|}
\hline Evaluation Criteria & $\mathrm{Y}$ & $\mathbf{N}$ & N/A & Comment \\
\hline $\begin{array}{l}\text { standard of facility design, LOS, connectivity, usage, } \\
\text { and connectivity to transit }\end{array}$ & & & & \\
\hline 9. $\quad$ Parking management & & & & \\
\hline 10. Transportation demand management & & & & \\
\hline 11. Broadband Internet access - availability & & & & \\
\hline 12. Baseline modal split of alternative modes & & & & \\
\hline $\begin{array}{l}\text { 13. Planned, programmed or committed improvements to } \\
\text { existing or new multimodal facilities including } \\
\text { documentation of designated corridor space for transit } \\
\text { or multimodal options }\end{array}$ & & & & \\
\hline $\begin{array}{l}\text { 14. Existing level of service for transit or multimodal } \\
\text { alternatives, if the local government or transit agency } \\
\text { has adopted such LOS standards }\end{array}$ & & & & \\
\hline $\begin{array}{l}\text { 15. Land use mix, including both employment and } \\
\text { residential, within the context of the DRI and the } \\
\text { surrounding community }\end{array}$ & & & & \\
\hline $\begin{array}{l}\text { 16. Land uses within the DRI that promote pedestrian, } \\
\text { bicycle, and transit use }\end{array}$ & & & & \\
\hline 17. *Sufficient densities to support transit ridership & & & & \\
\hline 18. *Sufficient intensity along major transit corridors & & & & \\
\hline 19. *Sufficient intensities in and around core areas & & & & \\
\hline 20. Connectivity to adjacent properties & & & & \\
\hline 21. Connectivity to transit & & & & \\
\hline $\begin{array}{l}\text { 22. Appropriate numbers of connections within the street } \\
\text { network }\end{array}$ & & & & \\
\hline $\begin{array}{l}\text { 23. *Shorter block lengths to support pedestrian } \\
\text { environment. }\end{array}$ & & & & \\
\hline $\begin{array}{l}\text { 24. Assessment of the reliability of selected trip generation } \\
\text { rates to predict the number of trips from the new } \\
\text { development }\end{array}$ & & & & \\
\hline 25. Identification of alternative sources of data, if applicable & & & & \\
\hline $\begin{array}{l}\text { Revise Section J as follows: } \\
\text { Section J: Multimodal Access to Surrounding Communit }\end{array}$ & & & & \\
\hline $\begin{array}{l}\text { 1. Inventory and document the degree of connectivity to } \\
\text { activity centers (areas with destinations such as } \\
\text { schools, shopping, recreational facilities, and other } \\
\text { points of attraction). Include crossing features and other } \\
\text { features (lighting, visibility, medians, pavement } \\
\text { markings) related to pedestrian/bicycle safety at each } \\
\text { intersection }\end{array}$ & & & & \\
\hline $\begin{array}{l}\text { 2. Identify all pedestrian and bicycle facilities, including } \\
\text { sidewalks shared roadways, signed-shared roadways, } \\
\text { bike lanes, or shared-use paths that lie within the site } \\
\text { access area, as designated in the [City/County } \\
\text { pedestrian/bicycle plan]. Identify gaps in the system }\end{array}$ & & & & \\
\hline $\begin{array}{l}\text { 3. Identify specific transportation network improvements } \\
\text { needed to provide safe and efficient pedestrian and } \\
\text { bicycle access from the project to activity centers }\end{array}$ & & & & \\
\hline $\begin{array}{l}\text { 4. Inventory and document the availability of public and } \\
\text { private transit service along routes to activity centers } \\
\text { within the study area or a minimum of } 5 \text { miles from the } \\
\text { DRI, whichever is further, including the location of bus } \\
\text { routes, frequency of service, hours of operation, } \\
\text { existing peak hour load factors, and bus stops and } \\
\text { amenities (concrete pad, bench, bus shelter and }\end{array}$ & & & & \\
\hline
\end{tabular}




\begin{tabular}{|c|c|c|c|c|}
\hline Evaluation Criteria & Y & $\mathbf{N}$ & N/A & Comment \\
\hline $\begin{array}{l}\text { connectivity to the sidewalk network) at existing and } \\
\text { programmed bus stops. The inventory must also } \\
\text { include lighting features (overhead streetlights) at } \\
\text { transit stops and nearby parking areas, as well as } \\
\text { availability (posting) of schedules or real-time transit } \\
\text { information }\end{array}$ & & & & \\
\hline $\begin{array}{l}\text { 5. List specific transit facility improvements contained in } \\
\text { the adopted [long range transportation plan, transit } \\
\text { development plan or public transit-human services } \\
\text { coordinated transportation plan] that address safe and } \\
\text { efficient transit access from the proposed development } \\
\text { to activity centers }\end{array}$ & & & & \\
\hline $\begin{array}{l}\text { 6. Identify specific transit-related facilities needed to } \\
\text { provide access to existing or planned transit service }\end{array}$ & & & & \\
\hline $\begin{array}{l}\text { 7. Minimize vehicular, transit, bicycle, or pedestrian } \\
\text { conflicts }\end{array}$ & & & & \\
\hline \multicolumn{5}{|l|}{$\begin{array}{l}\text { Revise Section } K \text { as follows: } \\
\text { Section K: Concurrency Alternatives }\end{array}$} \\
\hline $\begin{array}{l}\text { 1. Is the project within a transportation concurrency } \\
\text { exception area (TCEA) and in compliance with the } \\
\text { requirements of the TCEA? }\end{array}$ & & & & \\
\hline $\begin{array}{l}\text { 2. Is the project within a multimodal transportation district } \\
\text { (MMTD) and in compliance with the requirements? }\end{array}$ & & & & \\
\hline
\end{tabular}

* Criteria are found in applicable local or regional plans and regulatory mechanisms

In DRI Question 21 (F), applicants are asked to identify improvements to the highway network needed to accommodate impacts of the proposed DRI that cause facility LOS to fall below adopted standards. Rather than focusing on roadway capacity, the applicant may consider proposing multimodal solutions as mitigation for DRI impacts.

As previously discussed, mitigation for the impact of new DRI trips on the regional transportation system has historically been limited to contributions to or actual modification of roadway facilities. Applicants should be encouraged to consider measures such as the following as part of their mitigation efforts:

- Identify modifications to existing transit service, implementation of transportation demand management, as well as other modal considerations to maintain local and regional LOS standards. This may include the cost of extending transit service and associated amenities to the DRI (including operating costs where applicable). Develop cost estimates for such multimodal improvements.

- Provide alternate routes for short local trips to reduce congestion on major roadways.

- Increase the connectivity of the local street network to create walkable city blocks that enhance livability.

- Identify public/private resources to reduce employee

District 6 Mitigation Example

In south Florida, review

agencies have agreed to

mitigation strategies such as the

provision of transit bus stops in

or adjacent to developments,

particularly when they are

served by constrained roads

that would never be widened.

Key to acceptance of this

mitigation solution was

extensive coordination and

cooperation between the

Department and local

governments. 
While cost estimates for multimodal improvements needed to affect a mode shift may be initially higher than the cost of the comparable increment of highway improvement to serve those travelers, as multimodal facilities are put in place and the multimodal network is developed, the cost should decrease over time as later developments arrive. Similar to the circumstance where highway improvement costs impact the first developer to cause a highway capacity deficiency in an area, likewise, the first developer to commit to a targeted transit mode share may be tasked with higher costs of establishing the transit system. This circumstance may serve as a disincentive to build in the suburban fringe where there is often little or no existing transit service, or conversely, an incentive to build where multimodal services already exist.

In addition, DRI reviews often involve assessing projected long-term impacts over a time frame that exceeds local transit development plan horizons, even the ten year requirement. As such, a mechanism is needed to ensure that transit-based mitigation will continue over the long term.

Upon completion of the DRI ADA review, the FDOT reviewer should develop recommendations to ensure the developer mitigates the impact of the DRI on the transportation system. Again, there is no specific guidance in the "Site Impact Handbook" for development order conditions. To assist the reviewer, comments (noted in italics) have been taken verbatim from development order recommendation letters and may serve as guidance. Recommended conditions of approval should be clear about what is required and when it is required.

\section{- Scripps DRI ${ }^{12}$}

These comments, created by FDOT District Four's Office of Modal Development, are a first-time effort to incorporate multimodal strategies into a development order. The report outlines eight conditions that the applicant, Palm Beach County, must meet during the District 7 Mitigation Example Counties north of Tampa are home to many residents who work in Tampa and have no realistic transit options for traveling downtown. For example, providing bus rapid transit on Interstate 75 without an HOV lane or elevated structure has not been considered realistic; however, new methods include use of the shoulder for such purposes. Nevertheless, the Pasco County MPO was eager to explore transit and other multimodal options and set up meetings with appropriate agencies. Transportation demand management became a viable option when Pasco County accepted a park and ride facility as part of the mitigation plan/development order for the Wiregrass DRI. Meetings were held to best determine the facility location and the cost (estimated at $\$ 3,454,459$ ) was considered a part of their proportionate share payment. This mitigation strategy was a step in the right direction for the District. construction of the Scripps DRI, Palm Beach County Biotechnology Research Park (PBCBRP).

1. The applicant must demonstrate that the development can sustain an internal capture of at least 5,000 peak hour trips within PBCBRP and Palm Beach Gardens Science and Technology Community sites. The internal trips will be measured with each incremental phase prior to issuance of a building permit. A meeting with required agencies will be held in instances when the minimum number of internal trips per development phase is not achieved.

2. Design guidelines for the DRI must be adopted by reference into the County's Unified Land Development Code.

\footnotetext{
12 "Scripps Proposed Development Order Conditions (DRAFT)," Florida Department of Transportation. District Four Office of Modal Development, unpublished data. Ft. Lauderdale, June 11, 2004.
} 
3. Stipulations for the design guidelines are described, including transit and circulator service characteristics and criteria for constructing certain types of bus stops.

4. A deadline is given by which transit service is to be extended to the DRI, including accommodations for the site's non-standard work hours.

5. Construction of an intermodal transit center in the ADA with various user amenities proposed should commence construction with the issuance of the first building permit. The center should be designed to encourage a "park once” parking strategy.

6. Individual plats and site plans should develop and incorporate various parking strategies into their designs. These designs should promote long-term, aggregate, or shared parking, as well as connectivity of pedestrian and bicycle facilities.

7. "Cross-unders" must be constructed to provide connectivity between the Pedway System and PBCBRP.

8. Palm Beach County must either employ or contract with South Florida Commuter Services to employ an employee transportation coordinator prior to the issuance of the first certificate of occupancy.

\section{- $\quad$ Nocatee DRI ${ }^{13}$}

A review of the Nocatee DRI in St. Johns County generated recommendations from the Northeast Florida Regional Planning Council (NEFRPC) for inclusion in the subsequent development order. Each recommendation-inspired by NEFRPC's strategic regional policy plan-is preceded by a statement of anticipated consequences pertaining to a specific issue, should development impacts not be mitigated. NEFRPC's approval of the DRI is contingent upon the developer addressing each issue.

Three issues provide relevant references for development order condition statements: transportation data collection and analysis, bicycle and pedestrian connections, transit, and transportation management association. The Nocatee DRI applicant had already committed to bicycle and pedestrian connections in accordance with NEFRPC's policy, and the need for such a comprehensive system was reiterated in the recommended conditions:

1. Transportation data collection and analysis: Nocatee is designed to be a mixed-use community, with commitments to accommodate transit to increase internal trip capture. The internal capture rates supplied by the applicant exceeded the rate that FDOT typically recommends. NEFRPC therefore recommended that, four years after the start of construction and every three years thereafter, the developer collect data to accurately measure the development's actual internal capture rate exhibited prior to the start of each successive phase of development. The information will help determine how the remaining unallocated proportionate share contribution should be used. If possible, the reviewing agencies will consider transit improvements to mitigate the traffic impact of the successive development phases, in addition to other transportation options such as roadway widening.

\footnotetext{
13 “Recommendations for Nocatee DRI.” Northeast Florida Regional Planning Council. Jacksonville, FL, pages
} 31-34. 
2. Transit: Currently the Jacksonville Transportation Authority is the only provider of major fixed-route transit service in Northeast Florida. Over time as the region and areas outside of the City of Jacksonville grow, transit may become available to supplement future transportation needs. As such, Nocatee should be designed to accommodate transit as an option to single-occupancy vehicles (SOVs). Based on recommendations by NEFRPC, in addition to constructing the necessary facilities to make transit service possible, the applicant must provide information to future tenants and residents on the area's Metropolitan Commuter Assistance Program, administered by the governing MPO. Additionally, ridesharing and future transit information must be conspicuously displayed within the DRI.

3. Transportation management association: In an effort to discourage continuous roadway expansion without consideration of increasing automobile occupancy to solve transportation concerns, NEFRPC mandates that a Transportation Management Association (TMA) be created upon the issuance of permits for any development in Phase II of Nocatee. The TMA, to be comprised of major employers in the area, must work with review agencies to facilitate implementation of TDM measures, such as a shuttle service, carpooling, and flexible working hours. The TMA would also be encouraged to coordinate with employers and other DRI TMAs outside the Nocatee area. Activities of the TMA will be documented in an annual report and detailed in a traffic study to be conducted prior to implementation of Phase IV.

- Winter Garden Village at Fowler Groves ${ }^{14}$

The Development Order for the City of Winter Garden detailed the conditions under which the Winter Garden Village at Fowler Groves DRI must accommodate alternative transportation modes. It requires that pedestrian and bicycle facility designs facilitate access to structures such as theaters and commercial buildings and provide connectivity to existing external pedestrian and bicycle facilities. The development order also called for the creation of a Memorandum of Understanding (MOU) between the DRI developer and Central Florida Regional Transportation Authority (LYNX). ${ }^{15}$ In the MOU, the developer agrees to provide capital infrastructure as well as $\$ 300,000$ over two years toward operational support for at least one bus route to serve the DRI. Additionally, the development order required the developer to promote transportation demand management options within the DRI. The following conditions are verbatim:

Transit

1. LYNX service connecting the Project to existing routes shall be initiated within one (1) year of the opening of Phase 1 . The Developer will enter into a License Agreement with LYNX to facilitate the construction of stops for the service and coordination with LYNX. At a minimum, the Developer shall

\footnotetext{
${ }^{14}$ Sembler Winter Garden Partnership \#1, LTD. "Memorandum of Understanding Between Sembler Winter Garden Partnership \#1, LTD, and Central Florida Regional Transportation Authority for Winter Garden Village at Fowler Groves.” Florida, 2006.

${ }^{15}$ Ibid.
} 
facilitate, with funding if necessary, at least one transit route to be operational to the site for a period of two years.

2. Bicycle lockers or bicycle racks, transit passenger shelters and transit parking bays shall be constructed where necessary to augment and facilitate the operations of transit service to the site. Transit pull-out bays as required by the local government and LYNX on-site shall be constructed by the Developer. A site shall be provided for at least two future transit stops to accommodate buses at the location determined by the City and the Developer with input from LYNX in order to determine the appropriate number and location of pull-out bays and transit shelters. The Developer shall promote and encourage variable work hours and flextime participation by on-site employers. The Developer shall make known to tenants and residents that the Project has access to an existing ride-sharing program operated by LYNX. Transit and current ride-sharing information shall be prominently displayed in all public gathering areas, in employment centers and other areas as suggested by LYNX and Orange County. Tenants and owners within the employment centers shall be encouraged to provide preferential parking for vanpool/;(sic)carpools. The Developer shall propose to the City transit related actions, facilities, and sites within two (2) years of issuance of this Development Order after consultation with Orange County and LYNX. Transit access and right-of-way, if necessary, shall be provided to meet LYNX specifications to facilitate transit on site.

3. The Developer shall provide park and ride spaces either on site or purchase and construct a site for use as a rideshare lot to lessen the overall impacts on regional roadways. Spaces for at least 100 vehicles shall be provided and may be shared with parking for commercial land uses. The park and ride spaces shall be proximate to the bus transit stops when established. Park and ride spaces shall be aggregated into groupings of not less than 25 spaces per designated park and ride area, which shall be indicated with appropriate signage. The Developer shall coordinate with the City of Winter Garden, FDOT and LYNX to accomplish these requirements at the time of site development.

Pedestrian and Bicycle Traffic

In the interest of safety, and to promote alternative forms of transportation, the Developer shall provide an on-site system of bikeways and pedestrian circulation. Covered walkways shall be provided in front of stores and periodically across parking lots to provide protected walkways between banks or stores. The Developer shall construct a system of viable bikeways to interconnect all quadrants within the Project. In all areas of the Project, where cycling will be accomplished on both sidewalk/bikeways and streets, appropriate signage identifying bike routes will be installed. Special consideration shall be given to roadways connecting neighboring residential areas to onsite employment commercial centers. Bicycle support facilities (e.g., parking and lockers) shall be made available at theaters, commercial centers and work areas. The on-site bicycle systems shall be connected into any proximate external bicycle systems existing at the time of construction. Construction standards shall conform to latest state standards and criteria. Improvements to area roadways should be encouraged to incorporate bicycle 
and pedestrian facilities. New roadways or reconstructed roadways approaching the site include bicycle facilities.

\subsection{Local Government Development Order (LGDO) Review}

The local government with land use jurisdiction and permitting authority over the proposed DRI prepares a local government development order as the final approval in the DRI review process. According to the FDOT "Site Impact Handbook", the LGDO review "is the Department's final opportunity to assure that access to and LOS on SHS segments located in the project impact area are adequately protected.” As part of this assurance, FDOT staff should ensure that multimodal strategies and accompanying improvements are clearly addressed in the development order. In addition, the Handbook stresses that FDOT staff should ensure that the Department is named as a reviewer of required annual DRI monitoring.

Every effort should be made by FDOT reviewers to work with the regional planning council, local government staff, and other

"If the Department Reviewer believes that LGDO fails to adequately ensure the integrity of the SHS, the District's Director for Planning and Programming should be notified immediately. Objections to conditions of the LGDO must be appealed in writing to DCA within 45 days of the issuance of the LGDO. Objections expressed by the Department after this 45-day appeal period have no legal standing with DCA, RPC, or the applicant." FDOT "Site Impact Handbook" stakeholders to include enforceable development order conditions in the development order. In the event agreement cannot be reached, FDOT may submit a formal objection regarding the LGDO to DCA.

DRI Checklist 4, “Local Government Development Order Review Checklist,” addresses three areas of review including concerns related to approved land uses, concerns related to SHS access and LOS standards, and involvement in project monitoring. The addition of "transportation system connectivity" is the only recommended addition to the existing checklist (Table 6).

\section{TABLE 6 DRI Checklist 4. Local Government Development Order Review Checklist - Multimodal} Supplement

\begin{tabular}{|l|l|l|l|l|}
\hline \multicolumn{1}{|c|}{ Evaluation Criteria } & Y & N & N/A & \\
\hline Concerns Related to Approved Land Uses & & & & \\
\hline $\begin{array}{l}\text { Revise Section E as follows: } \\
\text { Section E. Internal traffic circulation plan, access points, } \\
\text { and transportation system connectivity revised to reflect } \\
\text { approved land use scenario(s)? }\end{array}$ & & & & \\
\hline
\end{tabular}

\subsection{Project Monitoring Report Review}

The FDOT "Site Impact Handbook” includes DRI Checklist 5 "Project Monitoring Review Checklist” to assist FDOT staff in performing this review. This report does not recommend any additions to this checklist; however, FDOT reviewers are strongly encouraged to review annual monitoring reports and provide written comments, when necessary, to the permitting local government. Such participation establishes FDOT as a champion of full implementation of a multimodal transportation system. The Handbook states, "The purpose of this review is to assure that the SHS LOS and access management standards are maintained throughout project implementation. The review also provides an opportunity to assure that LGDO-mandated transportation improvements are realized in a timely manner.'The local government development order should include specific requirements for project monitoring. FDOT staff should recommend 
appropriate monitoring for single occupancy vehicle use such as applicable measures from Table 7. Although project monitoring is an essential part of the DRI review process, research found that many FDOT reviewers forego this review. Reasons include time constraints and reliance on the fact that enforcement of development order conditions is a local government responsibility. At the same time, reviewers were frustrated that developers often failed to follow through specifically on multimodal considerations. For example, research revealed concerns that although many DRI applications indicate that the use of internal shuttles and ridesharing will be encouraged, no such actions are undertaken by the developer. If such situations were uncovered by FDOT staff or consultants reviewing the report, a letter could be sent to the local government alerting them of the omission. Such a letter may also include an offer of technical assistance if appropriate. In most cases, this review can be accomplished by reviewing information submitted by the developer; however, field observation may occasionally be warranted. Active FDOT participation in supporting development order conditions through DRI monitoring may make it easier for local governments to ensure compliance.

TABLE 7 Monitoring

\begin{tabular}{|c|c|}
\hline $\begin{array}{l}\text { Bus stops - Increase in bus stops with emphasis on } 1 / 4 \text { mile accessibility } \\
\text { to the population } \\
\text { - with shelters } \\
\text { - with bicycle parking }\end{array}$ & \\
\hline Transit revenue miles* & \\
\hline Intersecting transit routes & \\
\hline Park and ride locations & \\
\hline Multiuse path miles & \\
\hline Bike lane miles & \\
\hline Sidewalk miles & \\
\hline Pedestrian crosswalks & \\
\hline Traffic signals with pedestrian phase & \\
\hline Traffic signals with transit priority & \\
\hline Increase in transit peak hour capacity & \\
\hline Increase in transit rides per capita & \\
\hline Increase in transit passenger miles & \\
\hline Increase in passengers per revenue mile & \\
\hline Increase in ridesharing & \\
\hline Increase in telecommuting & \\
\hline Increase in use of alternative work hours & \\
\hline Increase in walking & \\
\hline Increase in bicycling & \\
\hline Decrease growth rate of VMT per person & \\
\hline Decrease growth rate of single occupant vehicle (SOV) mode share & \\
\hline
\end{tabular}

${ }^{*}$ Refers to the number of miles the transit vehicle is actually in service. 


\subsection{Notice of Proposed Change (NOPC) and Substantial Deviation Determination}

The "Site Impact Handbook" notes that the FDOT reviewer has a role in the review of each Notice of Proposed Change and Substantial Deviation Determination. The following verbatim examples illustrate issue areas from development order recommendations related to an NOPC and may serve as guidance:

\section{- LP Integrated Development Order ${ }^{16}$}

In response to a Notice of Proposed Change (NOPC), the City Commission of the City of Tallahassee drafted an integrated development order (DO) with a variety of specific conditions to be met by the developer, St. Joe Towns \& Resorts, LP. Within the set of conditions, six transportation demand management (TDM) strategies were issued for the developer, making provisions for:

- capital development transit including bus stops and shelters, and a satellite transfer facility;

- pedestrian and bicycle facilities, with criteria for constructing shower and locker facilities within the buildings of the DRI;

- a transportation coordinator, as appointed by the developer;

- $\quad$ preferential parking for high-occupancy vehicles, visitors, and the handicapped;

- $\quad$ pedestrian-friendly community design for areas within designated Pedestrian Primary Areas; and,

- $\quad$ resumption of a shuttle bus service to operate between this and an adjacent DRI, with connections to the local Tallahassee transit service.

\section{- Quillen DRI ${ }^{17}$}

In a response to the Treasure Coast Regional Planning Council regarding the Quillen DRI, FDOT District Four addressed the modal and design issues the applicant needed to take into consideration for approval. The following comments are excerpted from the memorandum:

1. Residential clusters shown in the Master Plan ... appear to reflect a traditional suburban environment. Coordination of land uses as well as internal street connectivity are important provisions in order to make progress towards providing travel choices other than by single occupant vehicles. Consideration should be given to increasing the grid pattern of local and regional roads to provide a variety of alternate routes.

2. The ADA indicates bicycle and pedestrian facilities will be provided; however, no maps are provided that demonstrate the accessibility of land uses to a bicycle/pedestrian system. It is important that bicycle and pedestrian facilities be created throughout the area to foster forms of mobility other than the single-occupant vehicle. In particular, bicycle and pedestrian access between residential areas,

\footnotetext{
16 "LP Integrated Development Order," City Commission of the City of Tallahassee, St. Joe Towns \& Resorts, 1999-2004, Florida, pages 29-31.

17 “Quillen DRI, Martin County; Application for Development Approval (ADA),” (interagency memorandum), Florida Department of Transportation, Planning and Environmental Management - District Four, Ft. Lauderdale, May 11, 2006, pages 3-4.
} 
commercial areas, and community facilities, such as parks and schools, should be included.

3. To address potential congestion, the applicant should also consider committing to the development and implementation of transportation demand management/commute trip reduction strategies to reduce project related peak hour automobile trips. The neighborhood center, in particular, provides an opportunity to support these types of programs. A park and ride lot for ridesharing/car pooling could be provided for to support future transit access. The objective is to relieve the regional roadway from local automobile trips that would otherwise be there.

4. Many of the previous comments also relate to making the community "Transit Ready." Transit service is available in Indiantown and expansion to the project should be considered. Many of the design principles described in the Indiantown Community Redevelopment Plan and Indiantown Design Regulations assist in promoting alternate modes of travel and establishing transit-ready and transit/pedestrian/bicycle-friendly communities. These principles include providing parking in the rear, locating buildings closer to the street, creating front porches to promote safety, providing pedestrian linkages, and establishing neighborhood greens or meeting areas.

\subsection{DRI Project Tracking}

Project tracking is important to measure the impact of an increased focus on incorporating transit and other multimodal solutions in the DRI review process. In many cases the regional planning councils provide mapping and tracking information regarding DRIs. Where this information is not available, FDOT staff should work with RPCs to ensure that DRI project status information is available to all parties on-line. In particular, DRI mapping could prove to be a useful tool for identifying proximate developments that could pool resources to improve transit to the area. In addition to tracking DRI conditions of approval that pertain to the State Highway System, each FDOT District should track multimodal components of the DRI. Such tracking will enable all FDOT reviewers including public transit to provide appropriate comments during annual reporting or other reporting cycles to assist local governments in the enforcement of development order conditions. 


\section{Cultural Shifts}

By Florida statute and rule, the FDOT role in the DRI review process is limited. The Department can influence inclusion of multimodal strategies in the DRI review process by expression of intention through an explicit policy statement. In addition, each district can increase its influence in the process by developing new or improving existing partnerships with local governments and transit agencies within the district. By taking a lead role in asserting the importance of transit and multimodal solutions to serve the DRI while maintaining adopted levels of service on regional facilities, FDOT is ushering in a cultural shift in how transportation facilities are planned and coordinated with the land development process. The Department will take a lead role in creating an expectation that transit and other modes should be part of transportation impact mitigation.

FDOT staff is committed to addressing and incorporating logical, appropriate multimodal planning solutions in the DRI review process as well as other avenues. The following guidelines focus on providing education and training, building relationships with local governments and other agencies, and conducting peer exchange meetings to share information.

\subsection{Education and Training}

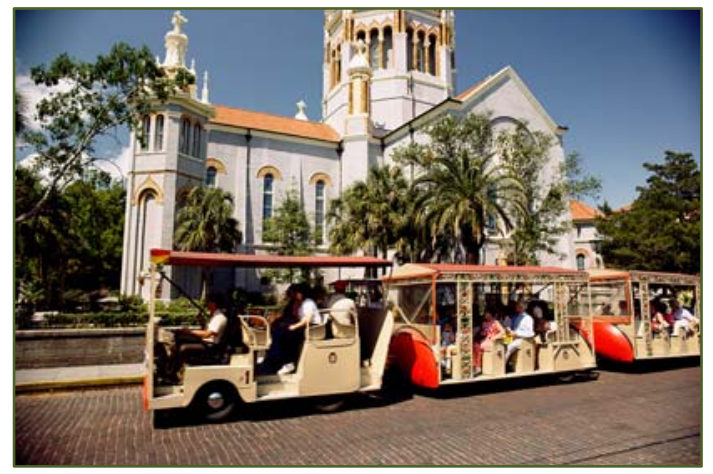

Through the evaluation of current practices and input received during the interview process, the need for additional education and training for those involved in the DRI review process became apparent. There were needs identified at several levels. First, the FDOT staff serving in the capacity of site impact coordinator or transportation planning engineer (as well as the consultant support staff) were found to be very knowledgeable about the review process itself, but inherent in their more traditional focus on infrastructure improvements, there wasn't necessarily a strong familiarity with the transit systems operating in the area.

Second, the FDOT public transit staff is generally familiar with the characteristics and needs of the transit systems within their respective districts, but that knowledge often goes untapped in terms of each District's review of DRIs for multimodal solutions. Finally, there was consensus that for the most part, the transit providers aren't proactive in their approach to DRI reviews, most likely as a result of their limited knowledge of the process. With this in mind, additional training should occur to address these needs. It was suggested that the periodic training for site impact coordinators is a good mechanism for continuing education, but that training might be more effective if it were conducted by peers who regularly review DRIs.

More basic training with a focus on the DRI process itself would be appropriate for FDOT public transit staff and public transit provider staff to help them gain an understanding of the process and determine appropriate opportunities for their input regarding multimodal considerations. Regional planning council representatives were often cited as the appropriate organization to conduct and/or facilitate the recommended training.

Not only should all FDOT District staff and consultants charged with reviewing DRIs receive training and education, but FDOT staff experienced in DRI review should also play a role in providing training. A role for FDOT in both education and training of the development community 
is necessary to activate the shift in transportation planning culture toward the expectation that transit play a role in the DRI review process and toward strengthening partnerships with transit agencies. This research process has uncovered that in general, transit agencies in Florida do not participate in DRI reviews because transit agency staff may lack the background in land development planning, lack the resources in labor hours to participate in the DRI review process and simply do not think to participate because they customarily have not in the past. In addition, the lack of transit agency regulatory powers leads them to assume that FDOT comments and requirements carry more weight. As such, FDOT's role in the education effort may be to create the expectation that the transit agency will participate in the entire DRI review process where transportation impacts have been identified as a regional issue.

FDOT's role should be to invite discussion of plans for transit services, markets, and needs in the vicinity of the DRI. Further, FDOT's role is to help translate the identified possibilities for transit into some initial development order conditions. Where there is no transit service or multimodal options to begin with, these conditions are on a scale of beginning steps, meant to break ground upon which transit service can build in the future. In addition, all reviewers should be aware that a unified approach from all review agencies regarding multimodal mitigation will carry more weight than any single agency making the request.

\subsection{Relationship Building}

Building and maintaining relationships with local government and other transportation partners is not only essential to coordination of the DRI review process but also to the development of regional mobility solutions. These relationships are mutually beneficial in meeting various statutory requirements including providing mobility on the Strategic Intermodal System (SIS) and providing adequate transportation facilities concurrent with the impacts of development. Genuine relationships that include regular communication will enable local governments and the FDOT to coordinate DRI reviews and work more strategically to meet mobility needs in a particular community or region. Establishing such relationships requires regular and consistent interaction by all agency representatives. At a minimum, the FDOT District staff should take a leadership role to initiate and maintain contact with each local government and transportation agency and to develop a mechanism to review development issues on a regular basis in accordance with the following guidelines:

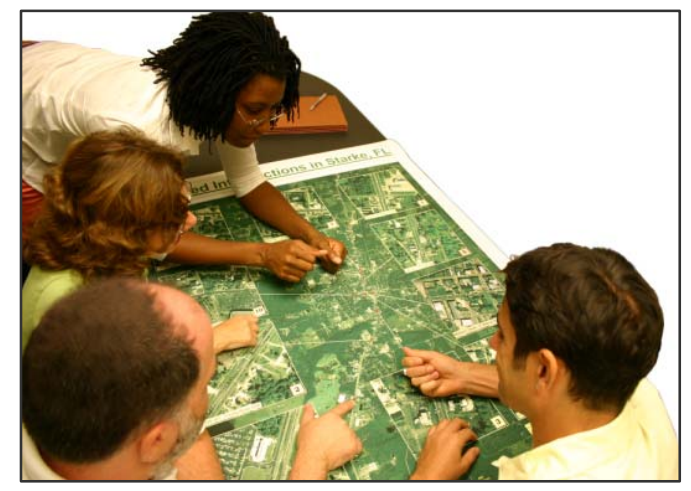

- Designate a small technical review group with expertise in land planning, development review, bicycle/pedestrian issues and transit operations, within each District DOT office who will serve as the liaison to the local governments for DRI review. The explicit role of this group is to devise a plan, in partnership with the transit agency, commuter assistance program or local transportation management association for initiating transit and other multimodal strategies to begin serving trips to and from the DRI, redirect local traffic off regional facilities and/or restore highway level of service. The names, position titles, addresses, telephone numbers, fax numbers, and email addresses should be furnished to local governments/agencies. Information regarding changes in personnel should be shared as soon as possible. 
- Request and participate in meetings, teleconferences, and/or other consistent methods of coordination regarding the potential impacts of a proposed DRI on the State Highway System, particularly facilities that are part of the Strategic Intermodal System or the Federal Interstate Highway System or facilities funded through the Transportation Regional Incentive Program. Most importantly, the FDOT technical review group representative designated above should attend the initial information meeting and the preapplication conference meeting prior to and including the traffic methodology meeting to ensure that transit solutions are considered from the start. This coordination should also address possible mitigation strategies with local governments/agencies and developers.

- Recommend a plan of transit and multimodal service initiation, both capital facilities and programmatic recommendations, to serve the DRI as part of conditions for development approval.

- Solicit feedback from all affected local governments/agencies regarding recommended conditions of approval. Although this function is already performed by regional planning councils for the purpose of incorporation into the regional report, it is important for all review agencies to be aware of other's comments. Increased awareness has the potential to lead not only to better solutions but to a united approach from reviewers regarding such mitigation.

- Appear before the permitting agency during the public hearing for the DRI to reinforce the importance of proposed conditions, if deemed appropriate.

- Follow-up annually with permitting agency to ensure development order conditions are being met.

\subsection{Multimodal Transportation Peer Exchange}

Lack of transportation funding and ever-increasing travel demand have lead local governments to realize that they cannot build their way out of congestion. Incorporation of transit and other multimodal solutions in the DRI review process as well as other development review processes is hampered by the lack of mutual understanding of the modal transportation vision among agencies participating in the DRI review process. Local governments and transportation agencies must work together to find and implement multimodal solutions to regional transportation challenges.

Development of multimodal solutions among transportation partners on a regional level may require a focused effort that is different from current planning forums. A "multimodal transportation peer exchange" may provide a new forum for multimodal planning efforts. This event is envisioned as a regional forum where peer-level representatives from an FDOT district, the regional planning council, metropolitan planning organizations, local governments, transit agencies, and developers can swap ideas, share best practices, and discuss challenges for their area. A general procedure for hosting a multimodal transportation peer exchange meeting is provided as Appendix G. It should be emphasized to all participants that the peer exchange is not intended to compare jurisdictions efforts with one another or to minimize any of a jurisdiction's activities.

FDOT Districts should consider hosting (or co-hosting) an annual meeting for their District or portions of the District. The peer exchange forum gives transportation partners the opportunity to highlight transportation accomplishments and plans, discuss challenges, and develop multimodal solutions to transportation. Some possible outcomes of such a forum may include:

- Identification of land use trends and/or pending growth areas; 
- Concepts for making future land use map changes for affordable housing, employment centers, or activity centers that may alter commuting patterns;

- Designation of dedicated transit corridors (bus rapid transit (BRT), streetcar, light rail/commuter rail);

- High employment zones that could implement TDM strategies to relieve congestion;

- Identification of bus route changes or expansions;

- Opportunities for multi-use trails;

- Location of bicycle/pedestrian needs to reduce congestion caused by local traffic;

- Improvement of street network connectivity;

- Bicycle and pedestrian concerns which are barriers to walking and cycling.

Once improvement needs are identified, transportation partners can work together to implement projects through comprehensive and long-range planning efforts, policy changes, and land development regulations and review processes. 


\section{Performance Measures}

Performance measures provide a way to evaluate the effectiveness of a program or process. In this case, FDOT seeks to ensure that reviewers fully consider the inclusion of transit and other multimodal alternatives throughout the DRI review process. To measure this, the following performance measure framework is recommended.

\section{Goal:}

FDOT staff/consultants actively address transit and other multimodal strategies throughout the DRI review process and related planning processes.

\section{Objectives:}

- FDOT staff/consultants participate in all DRI review meetings where land use and/or transportation are discussed.

DRI ADA requires that the

applicant should demonstrate

the DRIs consistency with the

State of Florida

Comprehensive Plan

(Chapter 187, F.S.), including

the goal that "Florida shall

direct future transportation

improvements to aid in the

management of growth and

shall have a state

transportation system that

integrates highway, air, mass

transit, and other

transportation modes."

- FDOT staff/consultants provide written comments, when applicable, regarding the consideration of multimodal strategies at appropriate times during the review process.

- DRI application for development approval (ADA) and transportation impact analysis address multimodal strategies as a substantive part of the transportation system.

- Final development order includes conditions of approval that address the inclusion of alternative modes, as appropriate, that are fully enforceable.

Using these objectives, appropriate performance indicators and targets were developed (see Table 8). FDOT District staff (including Public Transit Office staff) and consultants who perform DRI reviews will be responsible for recording this information for each DRI they are assigned. The ideal target for many of these performance indicators is 100 percent; however, lower targets may be more realistic for specific districts or areas once baseline measures are established. 
TABLE 8 Performance Measures for the DRI Review Process

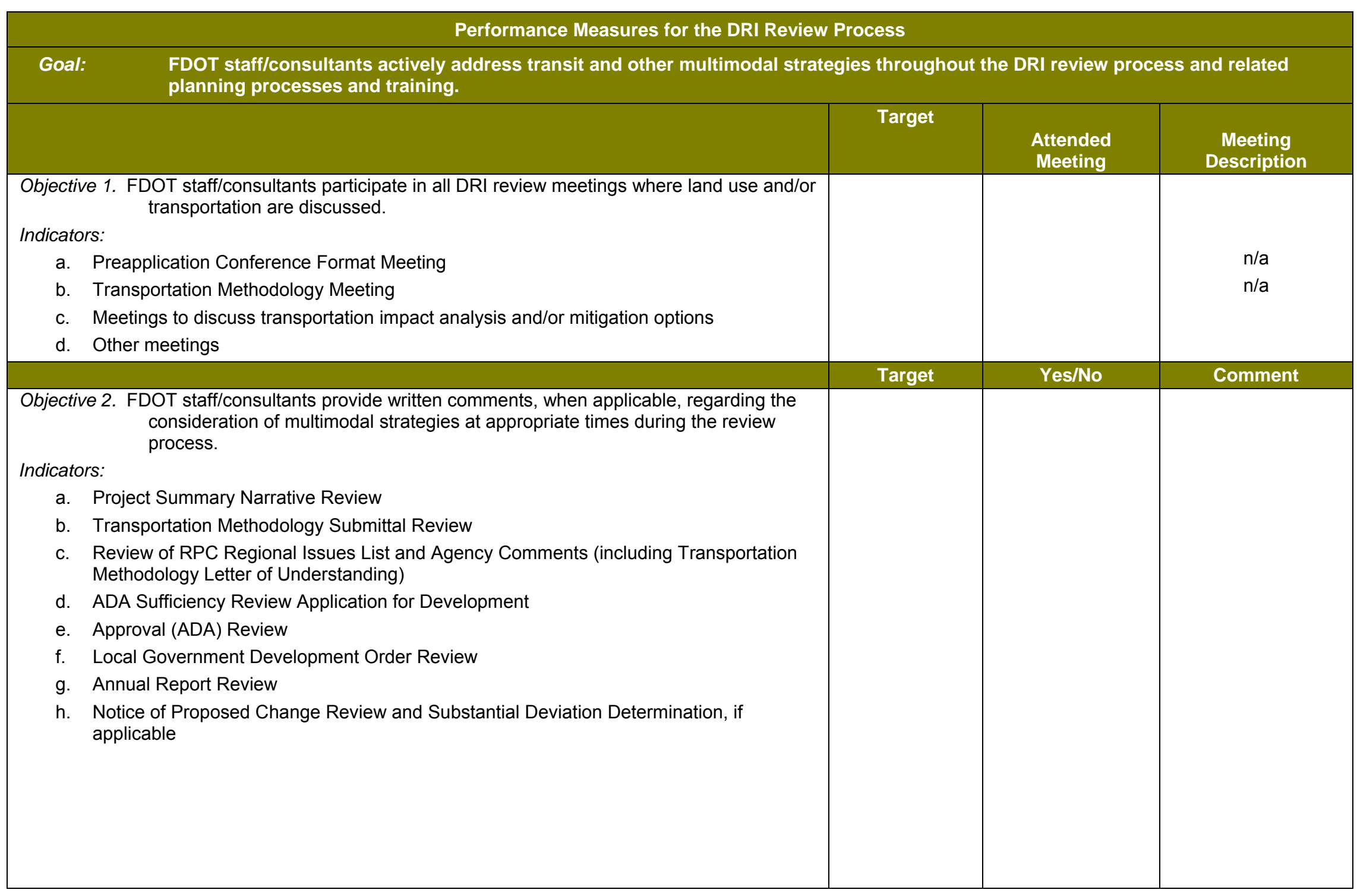




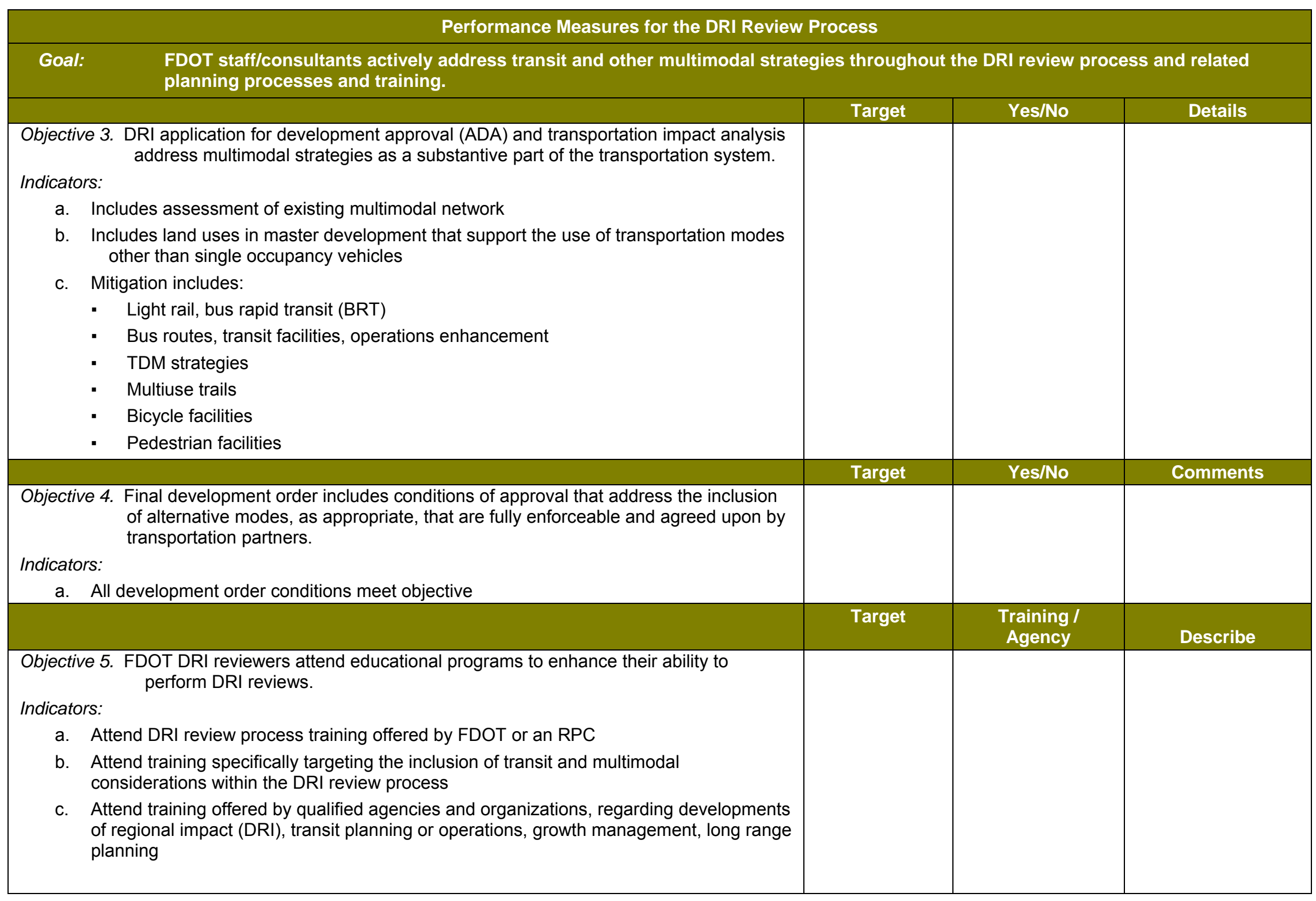




\begin{tabular}{|c|c|c|c|c|}
\hline \multicolumn{5}{|c|}{ Performance Measures for the DRI Review Process } \\
\hline \multirow[t]{2}{*}{ Goal: } & \multicolumn{4}{|c|}{$\begin{array}{l}\text { FDOT staff/consultants actively address transit and other multimodal strategies throughout the DRI review process and related } \\
\text { planning processes and training. }\end{array}$} \\
\hline & & Target & Training & urticipants \\
\hline \multicolumn{5}{|c|}{$\begin{array}{l}\text { Objective 6. FDOT district shall offer educational programs to transportation partners, } \\
\text { specifically transit agency staff and also staff members of local government, } \\
\text { RPCs, MPOs, and other transportation partners. }\end{array}$} \\
\hline \multicolumn{5}{|c|}{ Indicators: } \\
\hline \multicolumn{5}{|c|}{ a. DRI review process training } \\
\hline \multicolumn{5}{|c|}{$\begin{array}{l}\text { b. Training specifically targeting the inclusion of transit and multimodal considerations } \\
\text { within the DRI review process }\end{array}$} \\
\hline \multicolumn{5}{|c|}{ c. Training growth management, operations, long range planning } \\
\hline & & Target & Yes/No & Describe \\
\hline \\
\hline \multicolumn{5}{|c|}{$\begin{array}{l}\text { Indicators: } \\
\text { a. Establishment and maintenance of transportation partner contact list }\end{array}$} \\
\hline \multicolumn{5}{|c|}{$\begin{array}{l}\text { b. Initiation and maintenance of a small technical review group with all transportation } \\
\text { partners }\end{array}$} \\
\hline \multicolumn{5}{|c|}{$\begin{array}{l}\text { c. Meet regularly to discuss and review DRIs (twice a year minimum and more often where } \\
\text { there are a number of active DRIs) }\end{array}$} \\
\hline & & Target & Yes/No & Describe \\
\hline \multicolumn{5}{|c|}{$\begin{array}{l}\text { Objective 8. FDOT staff/consultants involved in development review participate in a multimodal } \\
\text { peer exchange meeting. }\end{array}$} \\
\hline \multicolumn{5}{|c|}{ Indicators: } \\
\hline \multicolumn{5}{|c|}{ a. Active involvement in hosting the peer exchange } \\
\hline \multicolumn{5}{|c|}{ b. Attendance at the peer exchange } \\
\hline \multicolumn{5}{|c|}{ c. Active participation during the peer exchange } \\
\hline d. & Active participation in follow-up activities & & & \\
\hline
\end{tabular}




\section{Conclusion}

The review process for developments of regional impact in Florida is a complex process that, in terms of transportation, has traditionally focused on mitigating the impact of vehicular traffic on the transportation system. A number of factors, including increases in traffic congestion along with decreased transportation funding, recent legislative requirements, and increased public demand, have led to both the need and desire to focus on alternative modes of transportation.

Research for this project revealed a lack of multimodal review guidance in the FDOT DRI Review Process as outlined in the FDOT "Site Impact Handbook". This report has provided guidance for incorporating transit and other multimodal strategies in the DRI Review Process. This guidance reflects the format of the "Site Impact Handbook" and emphasizes the importance of relationships with transportation partners and a shared, concrete future regional transportation plan. Adherence to these recommended guidelines by FDOT DRI reviewers, particularly those with technical expertise in alternative modes, will lead to an increased focus on a multimodal transportation system by all parties to the DRI review process.

Implementation of these guidelines will take some time. As a starting point, it is suggested that FDOT management communicate the importance of transit and other multimodal strategies as options for mitigating the transportation impacts of DRIs. This shift should be supported by education and training for staff, RPCs, local governments, consultants, and developers. FDOT staff should become familiar with local government plans, policies, and regulations that support alternatives to single occupancy vehicle travel and provide DRI applicants with all pertinent information. In addition, FDOT management should support enhanced interagency dialog, particularly a peer exchange. Such an exchange is necessary for transportation partners to develop a regional transportation vision that results in plans and specific improvements. Such improvements may serve as mitigation for development impacts and, therefore, be eligible for mitigation funding.

Additional factors outside the FDOT DRI review process contribute to the lack of multimodal focus in development review. Some examples are found in Florida statutes, rules, and development review guidance. Question 21, particularly 21(i), lends itself to limited responses from the applicant. Expanding Question 21 to be more inclusive of transit and other modes may be one way to increase the multimodal focus of DRI applications including mitigation measures. Rule 9J-2.045(7)(a) F.A.C. contains a list of the measures to mitigate the transportation impacts of a DRI. Mitigation measures are vague and seem to more readily address roadway improvements than multimodal improvements. Those that address alternative modes include only the provision for capital facilities for mass transportation or the provision for programs that provide alternatives to single occupancy vehicle travel. Future research may address greater attention to alternative modes for both Question 21 and the Rule 9J-2, F.A.C.

Local government long range plans often only minimally address alternative modes of transportation. Long range plans that detail the inclusion of alternative modes and supporting facilities are needed to foster an increased multimodal focus for all new development. Multimodal improvements found in such plans can provide a focus for the mitigation of development impacts on the transportation system. One opportunity to enable local governments to develop more robust transportation plans may be through the education and training of planners and elected officials. 
[This page left blank intentionally.] 


\section{References}

Florida Department of Transportation. "Improving Transit Involvement in Development Review." Florida State University College of Business, The Marketing Institute, Tallahassee, FL, 2002.

Florida Department of Transportation. "Site Impact Handbook.” Central Office Systems Planning Office, Tallahassee, FL, 1997.

Florida Department of Transportation. "Transit Involvement in Development Review Technical Memorandum \#1.” Florida State University College of Business, The Marketing Institute, Tallahassee, FL, 2002.

Grant, F. (2006). “Congestion Management Systems: Innovative Practices for Enhancing Transportation Planning.” TRB $85^{\text {th }}$ Annual Meeting CD-ROM.

Hiatt, R. (2006). “An Alternative to Auto LOS for Transportation Impact Analysis.” TRB 85 ${ }^{\text {th }}$ Annual Meeting CD-ROM.

Kramer, Jeff. "Review of MPO Long Range Transportation Plans and Regional MPO Planning Activities and Products: Research Support for the Florida Transportation Plan Update.” Center for Urban Transportation Research, University of South Florida, August 2005.

Pinellas County Metropolitan Planning Organization. "Identifying Transportation Needs, and Services for Older Adults, Persons with Disabilities, and Lower Income Individuals." Tri-County Access Plan, http://www.pinellascounty.org/mpo/tricounty.htm.

Seggerman, K. and Williams, K. (2006) "Impact Fee Credits for Livable Communities Improvements.” TRB $85^{\text {th }}$ Annual Meeting CD-ROM. 


\section{Appendix A - Interview Guide}

\section{General}

1. Approximately how many DRIs does your agency/District review annually?

2. How does your agency/District receive information about proposed DRIs?

3. Describe the organizational structure of your agency/District as it relates to DRI reviews.

4. Describe your role in reviewing DRI's and how you interact with others in your agency/District.

\section{DRI Review Processes and Practices}

5. Does your agency/District have specific guidelines/processes/procedures for DRI review?

a. FDOT "Minimum Responsibilities for District Development of Regional Impact Review"

b. FDOT "Site Impact Handbook"

6. What specific information do you give to applicants during pre-application or methodology meetings? (Can we have a copy?)

7. What guidance or techniques provided by your agency/District have been used by applicants?

8. How do you document your DRI review activities?

9. How do you handle continuity and consistency of DRI review from step to step?

10. Do you follow up with the responsible individual regarding issues or concerns identified through the DRI review process? If so, how does that process work?

11. What is your level of interaction with other agencies (local government, transit, MPO) involved in the review process?

12. At what point in the review process are critical decisions made regarding your agency's/District recommendations? Who makes these decisions?

13. Does your agency/District have the power to influence DRI conditions of approval or changes to the density/intensity/timing of the proposed development?

\section{Transit Consideration in DRI Review Process}

14. At what stage of the DRI process are transit alternatives considered?

15. What are your agency's/District's criteria for determining whether transit alternatives can be or should be explored?

16. How and to what degree does your agency/District encourage developers to incorporate transit alternatives into their plans?

17. In your opinion, what are the primary reasons for transit not being considered a viable option in some DRI transportation mitigation strategies? 
18. Once it has been determined that transit alternatives will be considered, what coordination mechanisms are set in place between your agency/District and other agencies?

19. How do you coordinate with the transit representatives in your agency/District and others in developing your recommendations?

\section{Development Orders/Monitoring}

20. In terms of final development order conditions, what is an ideal outcome from your agency's/District's point of view?

21. What is your process for follow-up regarding implementation of recommendations?

22. Describe your agency's/District's role in the monitoring process

23. Does your agency/District have any mechanisms for providing or receiving feedback on the transportation impacts of approved DRIs?

24. What is your level of satisfaction with the results of the DRI review process?

25. What are your agency's criteria for evaluating final transportation impacts of DRIs?

\section{Staff Resources/Expertise/Training}

26. Does your agency/District have adequate staff resources to review DRI's? How are resource deficiencies addressed?

27. Does your agency/District/position have explicit or implicit expectations for DRI review?

28. Do you measured or evaluated the effectiveness of your agency's/District's staff resources and/or expertise? If so, how? Were changes made to your DRI review activities as a result of the evaluation?

29. If not, do you have any ideas on how you might evaluate DRI review activities?

30. What type of training have you had in or related to the DRI review process including the consideration of transit? Was the training helpful?

31. Can you identify any tools/resources/training that you need to be more effective?

\section{Questions for FDOT staff if time permits}

32. What are your FDOT District's goals for developing and maintaining the State Highway System within the District?

33. Has it been articulated what, if any, role transit is planned to play in relation to the State Highway System?

34. How does your District differ from other Districts, with regard to transportation system development goals, funding, and development history?

35. What are your general observations about the nature of DRIs proposed within your District and the anticipated impact they have upon the State Highway System? 


\section{Appendix B - DRI Application for Development Approval Question 21}

Transportation road link/intersection:

Existing level of service:

Adopted level of service standard:

Level of service after each phase buildout:

A. Using Map J or a table as a base, indicate existing conditions on the highway network within the study area (as previously defined on Map J), including AADT, peak-hour trips, traffic split, levels of service and maximum service volumes for the adopted level of service (LOS). Identify the assumptions used in this analysis, including " $\mathrm{K}$ " factor, directional "D" factor, facility type, number of lanes and existing signal locations. (If levels of service are based on some methodology other than the most recent procedures of the Transportation Research Board and FDOT, this should be agreed upon at the preapplication conference stage.) Identify the adopted LOS standards of the FDOT and local government for roadways within the identified study area. For facilities on the Florida Intrastate Highway System, use the FDOT level of service standards for the analysis. Identify what improvements or new facilities within this study area are planned, programmed, or committed for improvement. Attach appropriate excerpts from published capital improvements plans, budgets and programs showing schedules and types of work and letters from the appropriate agencies stating the current status of the planned, programmed and committed improvements.

B. Provide a projection of vehicle trips expected to be generated by this development. State all standards and assumptions used, including trip end generation rates by land use types, sources of data, modal split, persons per vehicle, etc., as appropriate. The acceptable methodology to be used for projecting trip generation (including the Florida Standard Urban Model Structure or the Institute of Transportation Engineers trip generation rates) shall be determined at the preapplication conference stage.

C. Estimate the internal/external split for the generated trips at the end of each phase of development as identified in (B) above. Use the format below and include a discussion of what aspects of the development (i.e., provision of on-site shopping and recreation facilities, on-site employment opportunities, etc.) will account for this internal/external split. Provide supporting documentation showing how splits were estimated, such as the results of the Florida Standard Urban Transportation Model Structure (FSUTMS) model application. Describe the extent to which the proposed design and land use mix will foster a more cohesive, internally supported project.

INTERNAL/EXTERNAL SPLIT - VEHICLE TRIPS

\begin{tabular}{|c|c|c|c|c|}
\hline \multirow{2}{*}{ Phase } & \multicolumn{2}{|c|}{ Vehicle Trips (ADT) } & \multicolumn{2}{c|}{ Peak-Hour Vehicle Trips } \\
\cline { 2 - 5 } & Internal & External & Internal & \\
\hline Existing Phase 1 & & & & \\
$\cdot$ & & & & \\
\hline
\end{tabular}

D. Provide a projection of total peak hour traffic, background plus DRI traffic, on the highway network within the study area at the end of each phase of development. If these projections are based on a validated FSUTMS, state the source, date and network of the model and of the TAZ projections. If no standard model is available or some other model or procedure is used, 
describe it in detail and include documentation showing its validity. Describe the procedure used to estimate and distribute traffic with full DRI development in subzones at buildout and at interim phase-end years. These assignments may reflect the effects of any new road or improvements which are programmed in adopted capital improvements programs and/or comprehensive plans to be constructed during DRI construction; however, the inclusion of such roads should be clearly identified. Show these link projections on maps or tables of the study area network, one map or table for each phase-end year. Describe how these conclusions were reached.

E. Assign the trips generated by this development as shown in (B) and (C) above and show, on separate maps or tables for each phase-end year, the DRI traffic on each link of the thenexisting network within the study area. Include peak-hour trips. If local data is available, compare average trip lengths by purpose for the project and local jurisdiction. For the year of buildout and at the end of each phase estimate the percent impact, in terms of peak hour DRI trips/total peak hour trips and in terms of peak hour DRI trips/existing peak hour service volume for adopted LOS, on each regionally significant roadway in the study area. Identify facility type, number of lanes and projected signal locations for the regionally significant roads.

F. Based on the assignment of trips as shown in (D) and (E) above, what modifications in the highway network (including intersections) will be necessary at the end of each phase of development to attain and maintain the adopted level of service standards? Identify which of the above improvements are required by traffic not associated with the DRI at the end of each phase. For those improvements which will be needed earlier as a result of the DRI, indicate how much earlier. Where applicable, identify Transportation System Management (TSM) alternatives (e.g., signalization, one-way pairs, ridesharing, etc.) that will be used and any other measures necessary to mitigate other impacts such as increased maintenance due to a large number of truck movements.

G. Identify the anticipated number and general location of access points for driveways, median openings and roadways necessary to accommodate the proposed development. Please note which proposed access points are to be located on the State Highway System and must be permitted pursuant to Rules 14-96 or 14-97, Florida Administrative Code. Describe how the applicant's access plan will minimize the impacts of the proposed development and preserve or enhance traffic flow on the existing and proposed transportation system. This information will assist the applicant and governmental agencies in reaching conceptual agreement regarding the anticipated access points. While the ADA may constitute a conceptual review for access points, it is not a permit application and, therefore, the applicant is not required to include specific design requirements (geometry) until the time of permit application.

H. If applicable, describe how the project will complement the protection of existing, or development of proposed, transportation corridors designated by local governments in their comprehensive plans. In addition, identify what commitments will be made to protect the designated

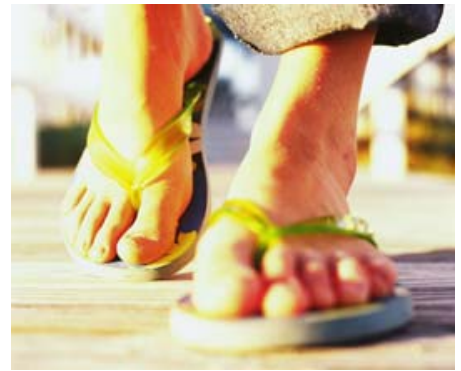
corridors such as interlocal agreements, right-of-way dedication, building set-backs, etc.

I. What provisions, including but not limited to sidewalks, bicycle paths, internal shuttles, ridesharing and public transit, will be made for the movement of people by means other than private automobile? Refer to internal design, site planning, parking provisions, location, etc. 


\section{Appendix C - Multimodal Information to be Provided or Made Available to DRI Applicant}

This Appendix provides details regarding the resources and documents listed in Table 1, Information Provided/Available to Applicant Checklist - Multimodal Supplement.

\section{Long Range Transportation Plan (LRTP)}

Metropolitan planning organizations (MPOs) across the nation undertake a long range transportation planning process that is continuing, cooperative and comprehensive, involving local government officials and other transportation stakeholders. The MPO planning process is guided by the Transportation Equity Act for the $21^{\text {st }}$ Century (TEA-21) and its predecessor, the Intermodal Surface Transportation Act (ISTEA) which “...shifted the focus of transportation planning away from narrowly addressing traffic congestion through new highway construction to holistically resolving identified transportation needs through enhanced multimodal transportation alternatives and improved long range transportation decision-making." 18

The majority of Florida MPO plans address the use of alternative modes of transportation including bike paths, sidewalks, multi-use trails, rail lines, bus rapid transit, express bus routes, and HOV lanes primarily via policy. A few MPOs, including the Tallahassee/Leon County MPO (now the Capital Region Transportation Planning Agency, CRTPA), the Broward County MPO, and the Gainesville Metropolitan Transportation Planning Organization (MTPO), have established unique approaches to promoting multimodal transportation systems in their 2020 LRTPs. The CRTPA “...conducted a twotiered walkability/bikability analysis to target bicycle and pedestrian enhancements to areas that have a high potential for bicycle and pedestrian activity.” The Broward County MPO Board included a significant number of transit-related improvements through complex alternatives testing which included both highway and transit alternatives. Finally, the Gainesville MTPO adopted a variety of multimodal projects including road connectivity projects, lane reductions to enhance pedestrian and bicycle facilities, as well as express bus service.

A review of the goals, objectives, and policies in MPO long range transportation plan updates reveal an emphasis on multimodal transportation solutions including the following generalized objectives:

- Change user behavior to accomplish reductions in SOV (single-occupant vehicle) dependency through increased vehicle occupancy, reduced peak period travel, and increased availability and use of alternative modes of travel.

- Make modal alternatives more viable through increased availability, improved service, and additional funding.

- Improve the connectivity of the transportation network through the provision of alternate routes.

- Promote livable communities through the design of a transportation system that is both sustainable and sensitive to community visions and values.

- Encourage local governments to adopt urban design strategies and corresponding land development regulations that support the integration of land use and transportation.

\footnotetext{
${ }^{18}$ Kramer, Jeff, “Review of MPO Long Range Transportation Plans and Regional MPO Planning Activities and Products: Research Support for the Florida Transportation Plan Update,” Center for Urban Transportation Research, University of South Florida, August 2005.
} 


\section{Local Government Comprehensive Plans (LGCP)}

Both authorized and required by the Chapter 163.3161, F.S., local governments in Florida prepare comprehensive plans to address land use and transportation, along with other required plan elements. Local government comprehensive plans (LGCPs) establish the policy direction of a jurisdiction's land development regulations. As with the MPO long range transportation plans, most goals, objectives, and policies of local government comprehensive plans, incorporate a variety of multimodal alternatives, site plan and subdivision design guidelines, and land development patterns that encourage livable communities while discouraging single-occupancy vehicle travel.

\section{Transit Development Plan}

Until recently, public transit agencies were required to prepare a five-year transit development plan (TDP) (with annual updates) as a condition of the receipt of State Block Grant funds. The newlyadopted Rule 14-73.001, F.A.C. requires transit development plans to include a ten-year horizon. Among other things, these plans identify all existing mobility services and outline plans for new service types, span and frequency improvements and service area expansion. For example, the plan may call for the addition of service into outlying parts of the county or the need for additional express routes and park and ride facilities to better serve the commuter market. The plans also identify the agency's goals, objectives and strategies necessary for more effective and efficient service delivery. For example, a priority may be the addition of more customer bus stop/shelter infrastructure or enhanced pedestrian accessibility to the passenger facilities.

The uncertainty of a relatively steady funding stream that many of the state's transit agencies experience has often made it difficult to closely align the transit providers needs and plans with those of a developer when build out of the various project phases may occur over as long as a 20+ year time frame. It is often a case of which comes first, the chicken or the egg? A developer may question the viability of constructing a bus stop, for example, in the absence of any transit service in close proximity to the site. Likewise, the transit operator may be reluctant to procure specialized vehicles to operate an internal circulator for a large development without a commitment for the necessary operating funds.

The applicable ten-year transit development plan or plans should be provided to developers at the preapplication meeting as a tool to enhance coordination between public and private sector transportation initiatives and facilitate greater consideration of transportation alternatives in the development review process.

\section{Locally developed coordinated public transit-human services transportation plan}

The following information is an excerpt from Pinellas County Metropolitan Planning Organization. "Identifying Transportation Needs, and Services for Older Adults, Persons with Disabilities, and Lower Income Individuals." Tri-County Access Plan, http://www.pinellascounty.org/mpo/tricounty.htm.

New federal legislation requires that all urbanized areas develop a coordinated public transit-human services transportation plan that:

- Identifies transportation needs of older adults, persons with disabilities, and individuals with lower incomes;

- Inventories existing transportation services available for these group;

- Identifies gaps and overlaps in existing services; and 
- Develops strategies to address the gaps and overlaps.

This plan is necessary for an area to receive funds under the New Freedom Program, the Jobs Access/Reverse Commute (JARC) Program, and the Elderly Individuals and Individuals with Disabilities Program. Together, the three programs provide limited grants for expanding public transit and other transportation services, buying vehicles, improving access to information and services, and other efforts. In order to involve the many stakeholders interested in transportation needs and services of older adults, persons with disabilities, and individuals with lower incomes in the development of the coordinated plan, a series of workshops will be held to obtain input on transportation needs, service gaps and overlaps, and solutions to address the gaps and overlaps.

\section{Transportation Demand Management}

Transportation demand management (TDM) consists of strategies that foster increased efficiency of the transportation system by influencing travel behavior by mode, time of day, frequency, trip length, regulation, route or cost. TDM discourages drive-alone travel through better management of existing transportation infrastructure, services and resources. TDM strategies include, for example, public transit services, carpooling, compressed work weeks, telecommuting, limited parking, and provision of bike and locker facilities by employers. Interest regarding methods of including TDM strategies in land development processes is growing among planning professionals. Extensive information can be found in the National TDM and Telework Clearinghouse at http://www.nctr.usf.edu/clearinghouse, TDM in Florida at http://www.commuterservices.com or the Victoria Transport Institute at http://www.vtpi.org/tdm/. The Clearinghouse contains over 100 case studies of work site trip reduction programs on the Helpdesk. 
TABLE C1 TDM Strategies in the Land Development Process

\begin{tabular}{|c|c|c|c|}
\hline $\begin{array}{c}\text { Means of } \\
\text { Influencing Travel } \\
\text { Behavior }\end{array}$ & $\begin{array}{l}\text { TDM Strategy } \\
\text { (examples) }\end{array}$ & $\begin{array}{l}\text { Supporting Action } \\
\text { (Land development process) }\end{array}$ & $\begin{array}{l}\text { Potential Implementing } \\
\text { Participants }\end{array}$ \\
\hline $\begin{array}{l}\text { Trip length } \\
\text { Reduce quantity of vehicle } \\
\text { miles. }\end{array}$ & $\begin{array}{l}\text { - Transit oriented } \\
\text { development } \\
\text { - Proximate commuting by } \\
\text { allowing employees to } \\
\text { relocate job to the branch } \\
\text { office nearest their homes }\end{array}$ & $\begin{array}{l}\text { Clustering related land uses and } \\
\text { providing an inter-connected } \\
\text { circulation system } \\
\text { (comprehensive plans and land } \\
\text { development regulations) } \\
\text { - Providing incentives to employers }\end{array}$ & $\begin{array}{l}\text { - } \text { Land developer } \\
\text { - } \text { Municipal land devt regulator } \\
\text { - } \text { Economic devt organization } \\
\text { - } \text { Realtors } \\
\text { - Employer } \\
\text { - } \text { Commuter assistance program } \\
\text { - } \text { Transp management assoc } \\
\end{array}$ \\
\hline $\begin{array}{l}\text { Mode } \\
\text { Increase efficiency of } \\
\text { system to carry more } \\
\text { people in the same } \\
\text { number of vehicles. }\end{array}$ & $\begin{array}{l}\text { - Developing land in support } \\
\text { of alternative modes, such } \\
\text { as transit oriented } \\
\text { development } \\
\text { - Limiting parking supply } \\
\text { - Offering alternative modes, } \\
\text { such as transit, vanpooling, } \\
\text { carpooling, bicycling, } \\
\text { walking } \\
\text { - Carsharing } \\
\text { - Road pricing }\end{array}$ & $\begin{array}{l}\text { - Locating land development to } \\
\text { take advantage of existing } \\
\text { underutilized transportation } \\
\text { services such as transit routes } \\
\text { - Providing on-site amenities, such } \\
\text { as lockers, showers, bicycle } \\
\text { parking and preferential carpool } \\
\text { parking (land development } \\
\text { regulations) } \\
\text { - Providing support services such } \\
\text { as marketing, ridematching and } \\
\text { guaranteed ride home } \\
\text { - Providing transportation services } \\
\text { and physical transportation } \\
\text { facilities off-site }\end{array}$ & $\begin{array}{l}\text { - Land developer } \\
\text { - Property manager } \\
\text { - Municipal land devt regulator } \\
\text { - Realtors } \\
\text { - Economic development } \\
\text { organizations } \\
\text { - Transit agency } \\
\text { - State DOT } \\
\text { - Municipal public works dept } \\
\text { - Municipal parks \& rec dept } \\
\text { - Employer } \\
\text { - Commuter assistance program } \\
\text { - Transp management assoc } \\
\text { - Private enterprise }\end{array}$ \\
\hline $\begin{array}{l}\text { Route } \\
\text { Bypass congestion. }\end{array}$ & $\begin{array}{l}\text { - Transit oriented } \\
\text { development } \\
\text { - Providing route alternatives } \\
\text { - High occupancy vehicle } \\
\text { lanes }\end{array}$ & $\begin{array}{l}\text { Providing a grid system, street } \\
\text { connectivity, and destinations } \\
\text { within easy walking distance } \\
\text { (comprehensive plans and land } \\
\text { development regulations) } \\
\text { - Implementing Advanced Traveler } \\
\text { Information Systems }\end{array}$ & $\begin{array}{l}\text { - Land developer } \\
\text { - Municipal land development } \\
\text { regulator } \\
\text { - Realtor } \\
\text { - Economic development } \\
\text { organization } \\
\text { - State DOT } \\
\text { - Municipal public works } \\
\text { - department } \\
\text { - Highway patrol } \\
\end{array}$ \\
\hline $\begin{array}{l}\text { Regulation } \\
\text { Mandate specific traffic } \\
\text { management actions or } \\
\text { outcomes by local } \\
\text { ordinance. }\end{array}$ & $\begin{array}{l}\text { - State growth management } \\
\text { provisions } \\
\text { - Concurrency } \\
\text { - Trip reduction ordinances } \\
\text { - Zoning ordinances } \\
\text { - Subdivision ordinances } \\
\text { - Parking ordinances } \\
\text { - HOV lanes }\end{array}$ & $\begin{array}{l}\text { - Carried out primarily by land } \\
\text { developers, property managers, } \\
\text { employers, neighborhood } \\
\text { associations }\end{array}$ & $\begin{array}{l}\text { - State land planning agency } \\
\text { - State DOT } \\
\text { - Municipal land development } \\
\text { regulator } \\
\text { - Municipal public works } \\
\text { department } \\
\text { - Municipal parking department } \\
\text { - Highway patrol }\end{array}$ \\
\hline $\begin{array}{l}\text { Cost } \\
\text { Establish incentives and } \\
\text { disincentives. }\end{array}$ & $\begin{array}{l}\text { - Parking pricing } \\
\text { - Transit subsidies } \\
\text { - Parking cash-out } \\
\text { - High occupancy toll lanes } \\
\text { - Commuter tax benefits }\end{array}$ & - Tax benefit program assistance & $\begin{array}{l}\text { - Property manager } \\
\text { - Municipal parking department } \\
\text { - State DOT } \\
\text { - Employers } \\
\text { - Commuter assistance programs } \\
\text { - Transp management assoc }\end{array}$ \\
\hline $\begin{array}{l}\text { Frequency } \\
\text { Reduce number of trips } \\
\text { over given time period. }\end{array}$ & $\begin{array}{l}\text { - Providing on-site amenities } \\
\text { - Compressed work week } \\
\text { - Telework }\end{array}$ & $\begin{array}{l}\text { - Providing physical facilities, such } \\
\text { as employee cafeteria, fitness } \\
\text { center, bank } \\
\text { - Providing technical support to } \\
\text { employers }\end{array}$ & $\begin{array}{l}\text { - Land developer } \\
\text { - Property manager } \\
\text { - Employer } \\
\text { - Commuter assistance program } \\
\text { - Transportation management assc }\end{array}$ \\
\hline $\begin{array}{l}\text { Time of daylday of week } \\
\text { Move trips to less } \\
\text { congested periods or } \\
\text { avoid vehicle trip } \\
\text { completely. }\end{array}$ & $\begin{array}{l}\text { - Compressed work week } \\
\text { - Staggered work hours } \\
\text { - Telework } \\
\text { - Flex time }\end{array}$ & $\begin{array}{l}\text { - Unbundling parking from } \\
\text { employment site leases } \\
\text { - Providing technical support to } \\
\text { employers }\end{array}$ & $\begin{array}{l}\text { - Property manager } \\
\text { - Commuter assistance program } \\
\text { - Transportation management } \\
\text { association } \\
\text { - Employer }\end{array}$ \\
\hline
\end{tabular}

Source: "Incorporating TDM into the Land Development Process, National Center for Transit Research at CUTR,” August 2005. 


\section{Commuter Assistance Programs}

Sponsored in whole or in part by the Florida Department of Transportation, there are several commuter assistance programs that serve various regions throughout the state. They are sometimes housed within a transit agency or managed by a private entity. These commuter assistance programs offer specialized mobility services and support programs to encourage the use of alternatives to single occupancy vehicle travel. Examples include subsidized employee/employer vanpools, carpool matching, guaranteed ride home, and reduced fare programs, to name a few. During the preapplication meeting, the developer should be made aware of any commuter assistance programs that currently serve or have the potential to serve the area of the proposed development.

\section{Design Manuals}

There are a number of resource manuals and guidelines that have been developed to guide the integration of various design features that enhance pedestrian, bicycle and transit circulation within a development. Some incorporate the specific requirements of the local jurisdictions while others are of a more generic nature and applicable to a broader geographic region. Based on the specific location of the DRI the relevant document(s) are another resource that should be provided at the pre-application meeting. Following are several examples of the available guidelines:

- FDOT District 4 Transit Facilities Guidelines Link: http://www.dot.state.fl.us/transit/Pages/UpdatedD4TransitFacilitiesGuidelines.pdf

- LYNX Central Florida Mobility Design Manual Link http://www.golynx.com/assets/userfiles/media/pdf/lynxdocs mobility manual.pdf

- LYNX Central Florida Customer Amenities Manual Link: http://www.golynx.com/assets/userfiles/media/pdf/lynxdocs Amenities Manual.pdf

- Palm Tran Transit Design Manual Link: http://www.pbcgov.com/palmtran/library/

- Accessing Transit Design Handbook for Florida Bus Passenger Facilities Link: http://www.dot.state.fl.us/transit/Pages/AccessingTransitHandbookLow.pdf

- Jacksonville Transportation Authority Mobility Access Program Handbook Link: http://www.jtaonthemove.com/workwithus/pdf/AccessProgram.pdf

- FDOT District 1 and 7 Transit Facility Handbook Link: http://www.dot.state.fl.us/transit/Pages/FDOT D1 D7 Transit Facility Handbook.pdf

Other Resources

- Leadership in Energy and Environmental Design Certification. U.S. Green Building Council. Link: http://www.usgbc.org/DisplayPage.aspx?CategorylD=19

LEED - Leadership in Energy and Environmental Design is a voluntary, consensus-based national rating system for developing high-performance, sustainable buildings. Based on well-founded scientific standards, LEED emphasizes state of the art strategies for sustainable site development, including alternative transportation. A project is a viable candidate for LEED certification if it can meet all prerequisites and achieve the minimum number of points to earn the certified level of LEED project certification. Achieving a LEED certified development will not only increase the marketability of a development, the inclusion of the following multimodal features will help meet multimodal development objectives. 


\section{Alternative Transportation: Public Transportation Access}

1. The building is located within $1 / 2$ mile [walking distance] of a commuter rail, light rail or subway station.

2. The building is located within $1 / 4$ mile [walking distance] of two or more public or campus bus lines usable by building occupants.

3. Building occupants are provided with a conveyance (shuttle link) that supplies transportation between the building and public transportation

\section{Alternative Transportation: Bicycle Storage and Changing Rooms}

1. For commercial or institutional buildings, provide secure bicycle storage with convenient changing/shower facilities (within 200 yards of the building) for regular building occupants. Maintain bike storage and shower capacity that is sufficient for the greater of $1 \%$ of the building occupants or $125 \%$ of peak demand for these facilities.

2. For residential buildings, provide covered storage facilities for securing bicycles for $15 \%$ or more of building occupants in lieu of changing/shower facilities. These facilities may be provided incrementally as long as the capacity of the facilities supplied exceeds the demand for these facilities.

\section{Alternative Transportation: Car Pooling and Telecommuting}

1. Provide preferred parking and implement/document programs and policies for car pools or van pools capable of serving $5 \%$ of the building occupants and add no new parking.

2. Operate an occupant telecommuting program over the performance period that reduces commuting frequency by $20 \%$ for $20 \%$ or more of the building occupants and provides the necessary communications infrastructure in the building to accommodate telecommuting.

3. Provide incentives for using car pooling or telecommuting to encourage occupants to reduce vehicle miles traveled. Include the option of telecommuting in the building design and size facilities appropriately. Encourage off-site work as this reduces office space requirements and employee facilities.

4. Encourage car pooling through initiatives such as preferred parking areas for high-occupancy vehicles (HOV) and the elimination of parking subsidies for non-car pool vehicles.

\section{Alternative Transportation: Parking Capacity}

Size motor vehicle parking capacity to meet, but not exceed, minimum local zoning requirements, AND, provide preferred parking for carpools or vanpools for $5 \%$ of the total provided parking spaces.

- Residential

Size parking capacity to not exceed minimum local zoning requirements, AND, provide infrastructure and support programs to facilitate shared vehicle usage such as carpool drop-off areas, designated parking for vanpools, or car-share services, ride boards, and shuttle services to mass transit. 
- $\quad$ Provide No New Parking

1. "Preferred parking" refers to the parking spots that are closest to the main entrance of the project (exclusive of spaces designated for handicapped) or parking passes provided at a discounted price.

2. Minimize parking lot/garage size. Consider sharing parking facilities with adjacent buildings. Consider alternatives that will limit the use of single occupancy vehicles.

\section{- "Incorporating TDM into the Land Development Process"}

National Center for Transit Research at CUTR/USF, August 2005

Link: http://www.nctr.usf.edu/pdf/576-11.pdf

This report, also developed by CUTR's National Center for Transit Research, aims to investigate proactive measures that TDM professionals can use to influence the incorporation of TDM into the land development process. It provides a review of available literature and policies related to various plans and regulations, analyzes relevant case studies that highlight negotiations between local governments and land developers, and outlines general findings as a result of the research.

The report offers suggestions to TDM professionals that include providing their expertise on the benefits of TDM in land development decisions to government officials and appropriate stakeholders. One recommendation calls for developing professional relationships. This is an opportunity where TDM professionals can encourage FDOT District staff to consider TDM measures that aid in improving mobility along state facilities within a given area.

\section{- “Land Developer Participation in Providing for Bus Transit Facilities/Operations"}

National Center for Transit R esearch at CUTR/USF, 2002

Link: http://www.nctr.usf.edu/pdf/Land\%20Developer.pdf

This report, developed by CUTR's National Center for Transit Research, documents various regulatory and non-regulatory strategies that Florida's local governments and transit agencies can use to generate public transportation funding. Funding would be generated through the involvement of private developers. Local and national case studies highlight some applications of these strategies that can be incorporated throughout Florida. The suggestions are designed for use within the framework of local government comprehensive plans (LGCPs), land development codes, and transit development plans, and therefore call for increased coordination and cooperation between local governments and transit agencies.

\section{- "Model Regulations and Plan Amendments for Multimodal Transportation District”}

National Center for Transit Research at CUTR/USF, 2004.

Link: http://www.dot.state.fl.us/planning/systems/sm/los/pdfs/MMTDregs.pdf

The report was prepared as a companion to the "Multimodal Transportation Districts and Areawide Quality of Service Handbook" (FDOT 2004). Multimodal transportation districts (MMTDs) are to be carried out through local comprehensive plans, land development regulations, and capital improvements programs. This report provides model comprehensive plan amendments and model regulations for multimodal transportation districts to assist local governments in Florida. It is based on a national review of multimodal policies, ordinances, and practices at the local level and a synthesis of best practices. The report begins with an overview of the purpose and statutory requirements for multimodal transportation districts in Florida, and continues with model comprehensive plan amendments and land development regulations to assist local governments in implementing MMTDs. 


\section{Appendix D - Multimodal Connectivity Analysis}

The following Multimodal Connectivity Analysis provides a format for DRI applicants to provide detailed information regarding how the proposed development will connect to existing activity centers.

Table D1 suggests the geographic area that should be analyzed in both urban and suburban scenarios; however, the size of the area and number of activity center routes to be analyzed may be modified according to the local environment and established during the pre-application meeting. Where DRIs are located in rural areas, review agencies should work with the developer to determine the appropriate areas of analysis during the pre-application meeting.

TABLE D1 Model DRI Multimodal Connectivity Analysis Areas for Urban or Suburban Areas

\begin{tabular}{|c|c|c|c|}
\hline \multicolumn{4}{|c|}{ Model DRI Multimodal Connectivity Analysis Areas for Urban or Suburban Areas } \\
\hline New Peak Hour Site Trips & $0-350$ & $351-500$ & $500+$ \\
\hline $\begin{array}{c}\text { Minimum Number of } \\
\text { Activity Center Routes } \\
\text { Evaluated }\end{array}$ & 1 & 2 & 3 \\
\hline $\begin{array}{c}\text { Accessibility to Activity } \\
\text { Centers }\end{array}$ & .25 mile radius & .35 mile radius & .50 mile radius \\
\hline
\end{tabular}

The goal of this analysis is to ensure that the site can be accessed safely and efficiently through various modes thus removing localized access from regional transportation facilities. Therefore, the following information should be provided by each applicant, particularly for facilities that are not considered part of the regional transportation system:

1. Inventory and evaluate the degree of multimodal connectivity to activity centers, which are areas with destinations such as schools, shopping, recreational facilities, and other points of attraction. Include crossing and other features (lighting, visibility, medians, pavement markings, and traffic control signals and signage) related to pedestrian/bicycle safety at each intersection.

2. Identify all pedestrian and bicycle facilities, including sidewalks shared roadways, signed-shared roadways, bike lanes, or shared-use paths that lie within the site impact study area, as designated in the [City/County pedestrian/bicycle plan]. Identify gaps in the system.

3. Identify specific transportation network improvements needed to provide safe and efficient pedestrian and bicycle access from the project to activity centers.

4. Analyze number of connections with the surrounding street system.

5. Conduct transit facilities analysis within the site impact study area.

6. Inventory the availability of public and private transit service along activity center routes, including the location of bus routes, frequency of service, hours of operation, existing daily ridership levels, and bus stops and amenities (concrete pad, bench, bus shelter and connectivity to the sidewalk network) at existing and programmed bus stops in the non-auto study area and note where applicable. The transit inventory must also include lighting features (overhead streetlights) at transit stops and nearby parking areas, as well as availability (posting) of schedules or real-time transit information.

7. List specific transit facility improvements contained in the locally developed coordinated public transit-human services transportation plan or transit development plan that address transit access from the proposed development to activity centers.

8. Identify specific transit-related facilities needed to provide access to existing or planned transit service. 


\section{Appendix E - Proposed Transportation Methodology Comments}

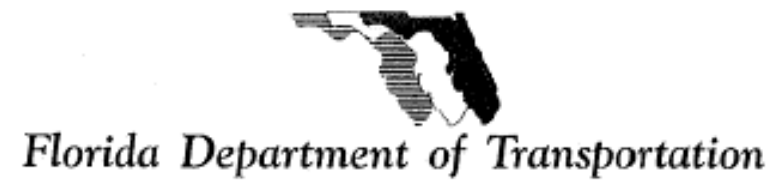
CHARLIF CRIST
GOVERNOK

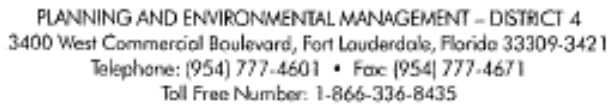

STEPHANIE C. KOPELOUSOS

SECRETARY

July 3,2007

Ms. Jo Sesodia, AICP

DRI Coordinator

South Florida Regional Planning Council

3440 Hollywood Boulevard, Suite 140

Hollywood, FL 33021

Dear Ms. Sesodia:

\section{SUBJECT: $\quad$ Lauderhill City Center Development of Regional Impact (DRI) City of Lauderhill, Broward County Proposed Transportation Methodology Comments}

As requested, the Department has reviewed the proposed transportation methodology for Lauderhill City Center DRI ADA, dated June 12, 2007.

The proposed mix-use development is currently occupied by the Lauderhill Mall located on the west side of SR-7/US-441, between $12^{\text {th }}$ Street and $16^{\text {th }}$ Street, north of Sunrise Boulevard. The development is to include approximately 2,500 multi-family residential units, 650,000 square feet of retail, and 425,000 square feet of office. The DRI is proposed to be built through three phases, by 2018, 2023, and 2033.

We have the following concerns regarding the methodology and its supporting documentations:

- Typically, only "transit" reduction is considered, not "multimodal" reduction. Of the claimed multimodal reduction of $15.5 \%$ and $11.4 \%$ for the AM and PM peak hours, respectively, only approximately $4 \%$ is associated with transit trips. Also, the surveys included in the Multi-Modal, Trip-Reduction, Justification Methodology memo can be difficult to verify.

- The discussed $30 \%$ internal capture is unusually high for the proposed development.

- The approximate claimed 58\% AM and 53\% PM total development trip reductions include multimodal, intemalization, and pass-by reductions. These exceed the maximum trip reduction attainable using methodologies outlined in the Site Impact Handbook.

However, we offer conditional acceptance of the proposed trip reductions based on the following:

wnw.dot.state.fl.us

(7) AETrago PAPER 
1. In the Application of Development Approval (ADA) document, the applicant shall commit to identify transit shelters, and other enhanced transit amenities based on the guidance contained in the District Four's Transit Facility Guidelines and guidance as provided through documented coordination with FDOT, Broward County MPO, and Broward County Transit.

a. The first two objectives in the Broward 2030 Long Range Transportation Plan Update (March 2005 ) include 1. Provide efficient, frequent, convenient, competitive transit service; and 2. Enhance bicycle and pedestrian mobility. Additionally, one of the major issues identified in the Broward County Comprehensive Plan Evaluation \& Appraisal Report relates to "Implementing Transit Oriented Land Use Pattems" and it is clearly evident based on the County's Transit Oriented Concurrency System and Comprehensive Plan that the County's future transportation system will rely heavily on alternative modes of transportation. As such, the ADA document should cstablish a modal split objective as a benchmark to evaluate transit, bicycle, and pedestrian features proposed as part of the DRI.

b. The applicant should include maps that identify the proposed master development plan land uses, street configuration, bus stop locations, and bicycle and pedestrian networks. This information is essential in assessing the degree to which land uses and transportation work together to maximize the use of transit, bicycle, and pedestrian facilities.

c. The applicant should include guidelines for placement and composition of shuttle/transit stops within the proposed development.

d. The applicant should address guidelines for locating kiosks that enable the posting of TDM program information in locations within the development that are readily visible to both employees and commuters.

- The posting of TDM information can vary based on the use of the property. This may include hanging wall kiosks, standing kiosks, table displays, etc.

- The purpose of posting the information is to provide commuters with information on the various transportation programs and services available at the development.

- Kiosks should be placed in readily visible locations such as public open spaces, lobby's, break rooms, cafeterias, elevator bays, building entrances, etc.

e. The applicant should elaborate on the use of a Designated individual to act as the employee development TDM coordinator known as the Employee Transportation Coordinator (ETC). The role of the ETC is to develop, implement, and administer a TDM program at the development. The ETC works closely with the various transportation providers in the region to accomplish goals set for the development

f. The applicant should commit to coordination with South Florida Commuter Services (SFCS) to discuss the various elements of available TDM programs and services. SFCS will provide the development with recommendations regarding TDM program clements that are appropriate for the site and steps to assist in implementing these initiatives. 
g. The applicant should commit to a protocol to introduce new owners or property management to the SFCS upon sale or lease of the development or properties within the development. This will allow SFCS an opportunity to inform them on TDM strategies, programs, and services.

h. The applicant should identify monthly subsidies and/or incentives (e.g., discounted transit passes, gas card for car pools, gift certificates, etc.) that will be considered for individuals participating in the use of alternative transportation modes.

- Providing subsidies and/or incentives equates to added benefits to commuters utilizing alternative transportation. These subsidies and/or incentives often reduce transportation costs and may encourage a commuter to begin utilizing an alternative mode of transportation or continue to motivate their use.

- Providing subsidies and/or incentives also benefits the employers in terms of employee recruitment and retention.

i. The applicant should specify the ability of the Master Plan to include ancillary uses for commuters such as day care, banking, dry cleaning and other on-site services that would climinate external trips.

j. Demonstrate how bicycle could be accommodated onsite. It is generally recommended that bicycle storage for both the long term (e.g., bicycle lockers) and short term (e.g., bicycle rack) be provided. The substantial deviation document should include guidelines for determining the placement of bicycle facilities and appropriate facility type based on adjacent land uses. Provides storage options for employees who may be working at the development to have a secured/covered location to store their bicycles in addition to providing a location for visitors to store their bicycle for a limited time.

k. Provide shower and locker facilities for buildings which employ more than 50 employees. Provides a location for bicyclists to store equipment necessary for biking, to shower, and to dress for work.

1. The applicant should account for modifications to the extemal roadway network that will improve the safety and attractiveness of pedestrian crossings at intersections along SR7/US441. This will help to maximize access to transit at stops on the opposite side of thoroughfares by creating a better environment for pedestrians.

m. It should be noted that the DRI documentation did not satisfactorily address parking provisions in line with the Transit Oriented Development. Large amounts of parking can have undesirable impacts on the pedestrian environment and increase the convenience of single occupant vehicles at the expense of using other modes of transportation. To be effective to reach the desired automobile trip reduction as projected on Page 1 of this letter, parking provision should be proportionally lowered below the city's minimum requirement. The applicant should consider orienting parking behind rather than in front of buildings and also consider more parking structures with pedestrian-oriented facades and first floor retail uses. 
2. The applicant shall include, as a condition in the Development Order, the provision of annual/biannual performance measures to ensure stated trip reductions occur. If trip reduction goals are not achieved, a traffic reassessment shall be required.

Please don't hesitate to give us a call if you have any questions or concerns.

GS:kai/lh/cw

Sincerely,

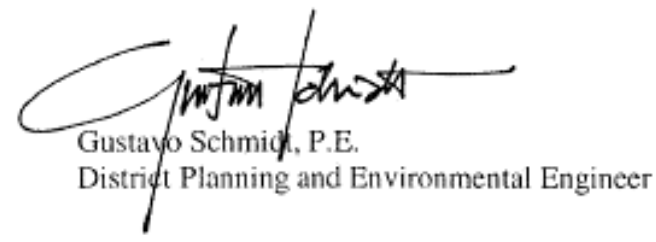

cc: D. Ray Eubanks, Community Program Administrator, FDCA

Bob Romig, Director, Office of Policy Planning, FDOT

Gerry O'Reilly, Director of Transportation Development, FDOT

Steve Braun, Assistant Planning and Environmental Engineer, FDOT

Shi-Chiang Li, Systems Planning Manager, FDOT

Chon Wong, Senior Transportation Specialist, FDOT 


\section{Appendix F - FDOT District 4 Example Office of Modal Development (OMD) Multimodal Sufficiency Comments}

The following sample sufficiency comments have been used in District 4 as general guidance on writing sufficiency comments.

\section{Alternative Transportation Modes}

The projected mode split of 3\% is consistent with the projected total number of PM Peak Hour trips (96) and Daily trips (977). This number of trips would support a "Hub" stop, which should be at locations with over 50 average daily boardings and serve multiple transit routes. (Gulfstream)

The applicant should more clearly define the bicycle, pedestrian, and transit facilities and services that are expected to serve the DRI so that the planning and provision of these facilities and services can be addressed in a comprehensive manner, rather than wait for future piecemeal site plan review as indicated on page ... Key parking areas and parking strategies should also be identified to aid in assessing how this infrastructure affects the encouragement of alternative modes of travel. (Provences)

The applicant should coordinate with the St. Lucie Council on Aging, to discuss the potential for future extension of existing transit service to the development and the future establishment of a transit transfer and ridesharing facility, if this is determined to be needed. Such discussion should be documented and reported as part of the ADA. (Provences)

\section{Transportation Demand Management Strategies (TDM)}

A commitment to use Transportation Demand Management (TDM) strategies and related details regarding those strategies should be included in Question 21(i) of the application. Some strategies include, but are not limited to the following: (Gulfstream)

- An Employee Transportation Coordinator employed on-site who will actively coordinate with South Florida Commuter Services and offer them the opportunity to review and comment on TDM activities.

- Identification and designation of specific areas with close access to particular jobsites for employees who carpool/vanpool to work.

- Location and installation of kiosks within the facility to provide transportation related information and options on carpooling, vanpooling, bus/transit schedules, and maps.

- Management of a "Guaranteed Ride Home Program" for car/vanpoolers.

\section{Attainable/Affordable Housing Located in Close Proximity to Accessible Travel Choice Options}

Not yet applied. [Although this has not yet been applied in the District, there is a direct connection. Affordable housing should be located within close proximity to existing transit options rather than being built with the expectation that transit agencies will make the service available after the housing in built.]

\section{Parking Provisions}

It should also be noted that there appears to be a large amount of surface parking shown in ... This can have undesirable impacts on the pedestrian environment, discourage a "park once" approach to reducing auto trips, and increase the convenience of single occupant vehicles at the expense of using other modes of transportation. The applicant should consider orienting parking behind rather than in 
front of buildings and also consider more parking structures with pedestrian oriented facades and first floor retail uses. (Provences)

\section{$\underline{\text { Site Planning/Balanced Land Uses }}$}

Seminole Pratt Whitney Road runs through the middle of a land use focal point (town center), which functions as a major attractor of trips and will discourage potential internalization of trips within the site. This project in large part relies on Seminole Pratt Whitney road as the major north/south artery for movement of trips. This road is projected to fail. Alternate land use scenarios should be considered to internalize trips to a greater extent. (Gallery-Judge Grove)

The spatial relationship between the proposed multiple family residential and other proposed uses such as the school and the Traditional Neighborhood Development (TND) should be depicted on Map H as part of the Master Development Plan to justify claims in Question 21i that this scenario complies with the characteristics of a TND. (Indrio Groves)

The realignment of Koblegard Road, by protruding to such an extent within the DRI in lieu of bordering the property, may preclude the ability of future development on adjacent vacant land to the east from having access to distribute traffic in an efficient manner. Maximizing roadway connectivity aids in the distribution of traffic. (Indrio Groves)

The applicant should consider a redistribution of commercial land use to be located at the intersection of the spine road and Spanish Lakes Boulevard. Do to the substantial number of residents in the Spanish Lakes Fairways development, providing commercial land uses at this location to serve the home-based shopping trip purposes of this community and Indrio Groves will help to reduce trips on Indrio Road by shorten trip lengths due to its closer proximity. (Indrio Groves)

\section{$\underline{\text { Internal Design }}$}

In order to foster desirable characteristics that result in sustainable development, including access to various modes of travel from adjacent land uses, the DRI applicant should be required to develop design guidelines that demonstrate how urban design, land use, and roadway characteristics will result in optimal mobility for the project and beyond. Such design guidelines should function to illustrate how development will aid in the provision of pedestrian, bicycle, and transit infrastructure as well as convenient connectivity for a quality experience sufficient to capture choice participants. Some components of design guidelines include, but are not limited to: (Indrio Groves)

- building design

- building scale

- density/intensity

- street patterns

- street widths

- landscaping

- activity centers that are attractive, pedestrian-friendly, and serve surrounding neighborhood-level

- residential areas

- parking
- activity nodes with higher density/intensity

- healthy mix of uses within easy walking distance of each other

- sidewalks

- pedestrian-friendly block sizes (e.g., block face no more than $500 \mathrm{ft}$, average block perimeter 1,350 ft)

- traffic calming measures

- transit, pedestrian, and bicycle infrastructure $\&$ access to those facilities 


\section{Appendix G - Hosting a Multimodal Solutions Peer Exchange Meeting}

\section{Purpose}

A peer exchange meeting offers a forum for highlighting transportation accomplishments, discussing challenges, and developing solutions. It should be emphasized to all participants that the peer exchange is not intended to compare jurisdictions efforts with one another or to minimize any of a jurisdiction's activities.

\section{Preparing for a peer exchange meeting}

1. Identify co-hosts - Identify local governments or other agencies interested in co-hosting the event. The regional planning council (RPC) might be a natural fit for this role.

2. Consider securing one or more professional facilitators to assist with the event.

3. Begin planning 6-12 months prior to meeting date.

4. Plan for a one-day event; however may be extended if organizers deem appropriate

5. Choose an event date.

- Preferred dates may be when FDOT/local governments are in middle of their fiscal year so the results of this effort may be incorporated into the upcoming fiscal year budget

- Avoid days when city/county commissions are meeting to maximize participation

6. Establish participant fee (registration fee) to cover cost of meals, etc. (Note: State funds cannot be used for providing food.) Identify an agency that can collect these fees and make necessary payments.

7. Prepare list of invitees. The size of this meeting will depend largely on the size of the area being targeted. Ideally, this is a group of a 24 to 48 people that can identify areas of concern with the transportation system and work to develop multimodal solutions. Participants should include those with some decision-making power as well as those charged with implementing decisions.

Suggested invitees are listed below and should include anyone who could bring efforts to a halt if not included as part of the process.)

- Majority of invitees should be representatives from:

o FDOT Districts

o Local governments (i.e., planners, public works, traffic engineers)

o Regional planning councils

o Metropolitan planning organizations

o Transit agencies and operators, including paratransit

o Commuter assistance programs and transportation management associations

o Bicycle/pedestrian program representatives

o School district facility planning and transportation departments

o Industry representatives (i.e., freight, land developers, builders associations, etc.)

o Large employers or institutions (i.e., military bases, universities, etc.)

- Local legislators/elected officials

- School board 
- AARP or local seniors representative

- Council of neighborhoods representative

- Media, including local news broadcasters, periodicals, radio stations and trade publications

8. Select and secure a meeting location based on the number of anticipated participants. The facility should be compliant with the Americans with Disabilities Act (ADA).

- Possible locations include FDOT District, RPC, or MPO office (Note: If transit available, encourage participants to travel via that mode to raise awareness of multimodal concerns)

- Room set-up: Ideally, the meeting room set-up includes round tables that enable participants to view the front of the room and have small group discussions.

- Telecommunications; the meeting location should have ability to be setup for teleconferencing.

9. Secure speakers. A keynote speaker and speakers from each participant group having issues to share should be identified and secured for the chosen date.

10. Prepare meeting materials (handouts, nametags, name tents, etc.). Allow adequate time for review and printing.

\section{Meeting Day Logistics}

1. Registration desk. Participants will sign in and receive meeting materials and nametag.

2. Include onsite continental breakfast, lunch, and morning and afternoon coffee breaks. It is important to keep attendees on-site for the day for continuity and to keep participants "on task." The lunch may be a working lunch; however, some time for phone calls, etc. should be included.

\section{Meeting Format}

The professional facilitator should establish ground rules for participation. To make this a candid problem solving and trouble shooting working session, attendees need to feel safe to express concerns and this may be difficult if the problems involve coordination issues or if there is a fear of finger pointing.

1. Welcome (possibly Keynote Speaker), introductions, explain the meeting. Select a theme, issue or agenda to provide a point of departure for initially focusing the discussion or to get the conversation off the ground. Use an "Icebreaker" technique to create a comfortable atmosphere and stress that this regional group is all "on the same team."

2. Clearly define the need for multimodal solutions and the expertise of all participants to develop a workable mobility plan.

3. Transportation system status with emphasis on multimodal efforts. Participants should be encouraged to be candid about challenges and issues rather than presenting a rosy picture; avoid finger-pointing. Each participant should be prepared to share details of the agency:

- Accomplishments or "what has worked well" for the agency (of the past year or 5 years for first meeting)

- Plans for the coming year. (Include long range plan information such as future land use map (FLUM) changes, transportation or traffic circulation elements, and capital improvement elements) 
- Challenges, areas of concern, or "what needs refining." This should also identify where the agency feels need additional coordination or help from this "Peer group." These could be tied to the specific topics of review process timing/chronology, criteria for review, staffing resources, data needs, lessons learned, etc.

o Input from participants is critical in this area because the remainder of the meeting is devoted to developing solutions for areas of concern.

- Use a facilitator to capture the area of concern and prioritize for the following breakout sessions.

4. Breakout discussions.

- Organize breakout discussions as appropriate. Provide a facilitator and recorder for each group.

- Each group will be devoted to "brainstorming” solutions to identified areas of concern through a facilitated open dialogue. Solutions should be of a multimodal nature involving more than one agency.

- Ask each group to report its suggestions to the broader group. Narrow suggested solutions, if necessary, to an appropriate number of key solutions through an iterative combining/ranking process.

5. Concluding activity - development of action plans.

- Reconvene breakout groups using the basic process above.

- Provide each group with an appropriate number of solutions to address. For each solution ask the group to identify a list of actions needed to advance that solution. Outcomes may include changes in review processes, programming of a corridor management plan, a strategic transit plan, etc.

- Join the groups and review the list of actions for each solution together. Combine similar actions and/or rank them if necessary to establish a short list of key actions.

- Agree upon role of each agency in implementing key actions, a timeline, if appropriate, and identify how they will know if the action is being accomplished.

6. Post meeting activity.

- Produce an action plan and send it to each participant for a final review and additional comment period. Provide each agency with the following:

o The final suggested action plan. Encourage formal agency actions to advance the plan (e.g., adoption through intergovernmental agreement).

o Contact information of all participants for future exchanges.

- The action plan may be used as an evaluation tool by meeting hosts or participants prior to the next annual meeting or schedule follow-up meetings.

7. Evaluation

- The moderator should record:

o Attendance at peer exchange; 
o Attendance compared to a targeted list of parties;

o Representation of meeting attendees across various coordinating agencies and municipalities

o Active participation during meeting (presence of debate);

o Evidence of search for and expression of common ground, such as ideal outcome;

o Identified next steps;

o Distribution of meeting debriefing and a list of contacts.

- In addition, it would be fruitful for peer exchange participants to complete an evaluation form. The moderator should then combine and analyze these evaluations. Evaluations may address:

o Skilled impartial meeting moderator

o Appropriate mix of attendees

o Candid discussion of issues

o Ability of attendees of all perspectives to express disagreement

o Disagreement results in further explanation of perspectives and problem solving

o Evidence of search for and expression of common ground, such as ideal outcome

o Contribution from all attendees (or were some individuals or groups noticeably silent?)

o Consensus on the issue

o Identification of next steps

o Identification of enhanced agency roles

o Attendees volunteered to take on follow-up roles

o Steps made to make coordination easier and more effective

o Increased contact among agencies

o Most notable meeting results

o Improvements for next year 